\title{
Modeling the membrane formation of novel PVA membranes for predicting the composition path and their final morphology
}

Denis Bouyer ${ }^{* 1}$, Oualid $\mathrm{M}^{\prime}$ Barki $^{1}$, Céline Pochat-Bohatier ${ }^{1}$, Catherine Faur ${ }^{1}$, Eddy Petit ${ }^{1}$, Patrick Guenoun ${ }^{2}$

${ }^{1}$ IEM (Institut Européen des Membranes), UMR 5635 (CNRS-ENSCM-UM), Université Montpellier, Place E. Bataillon, F-34095 Montpellier, France

${ }^{2}$ LIONS, NIMBE, CEA, CNRS, Université Paris Saclay F-91191 Gif-sur-Yvette, France

\begin{abstract}
Herein, a numerical model is developed for investigating the appropriate operating conditions for obtaining porous membranes from PVA/water system. The main interest of such novel polymeric system lies in the use of water as solvent instead of classical organic solvent. In that context, the membrane formation involves three coupled and interdependent phenomena: phase inversion, crosslinking and solvent evaporation. The mass transfer model involves thermodynamic description by Flory-Huggins theory, specific diffusion formalism for dilute system and external mass transfers in free convection. Since the system evolves from monophasic to diphasic region during membrane formation, the diffusion formalisms were adjusted depending on the composition path to simulate the solvent and catalyzer evaporation. The simulations exhibit that due to mass transfers occurring concomitantly to phase inversion and crosslinking, the operating conditions (final temperature, catalyzer, initial solution thickness) must be carefully chosen to ensure the formation of a porous membrane with PVA/water system.
\end{abstract}


Keywords: Membrane materials; Simulation, multiscale; Green engineering; Mass transfer

\section{Introduction}

Polymeric membranes are usually fabricated by phase inversion methods: a thermodynamic instability is provoked from homogeneous polymeric system by temperature and/or composition change, thus inducing the formation of a lean polymer phase (the pores of the membrane after solvent extraction) and a rich polymer phase ${ }^{1,2,3}$. Dry casting method, which involves a polymer/solvent/non-solvent system, was the earliest method used to prepare polymeric membranes. The composition path of the system is initially within the monophasic region (homogeneous polymer solution) and then different evaporation rates between the solvent and the non-solvent lead to a phase inversion once the composition path enters the diphasic region. Starting from a binary polymer/solvent system, TIPS (Thermally Induced Phase Separation) is another method based on rapid temperature decrease below the UCST (Upper Critical Solution Temperature) of the system ${ }^{4,5,6,7}$. Nowadays, the most common phase separation method for manufacturing polymeric membranes is NIPS (Non-solvent Induced Phase Separation) method, which involves non-solvent intake into a polymer/solvent system. Water is classically used as the non-solvent and NIPS can be divided in two processes: (i) wet process (or immersion process) that consists of immersing the polymer solution (collodion) into a water bath ${ }^{8,9,10}$ and (ii) VIPS (Vapor Induced Phase Separation) process where the collodion is exposed to humid vapors $^{11,12}$. VIPS process allows preventing the formation of macrovoids since the mass transfers occurring during the process, i.e. water intake and solvent extraction, are strongly reduced ${ }^{13,14,15}$.

As a consequence, phase separation using non-solvent coagulation of a polymer solution being the most widespread industrial process to manufacture membranes, large solvent quantity is then use that it complicates the overall process and may lead to environmental and health problems. Knowing that polymer concentration is usually in the range $15-20 \%$ and coagulation and washing baths require to be often renewed, large amounts of aqueous solutions must be treated. Recently, a novel generation 
of membranes, based on an original phase inversion method and using water-soluble polymer has been developed by our group ${ }^{16}$. Our objective was to develop a novel process for membrane mass production in agreement with the principles of green chemistry. The main technical and economic output of using water instead organic solvents should consist in a simplification of the manufacturing process by lowering wastes and recycling. The aim is to prepare membranes using either water-soluble commercial polymer like PVA presenting a lower critical solution temperature (LCST). Consolidation of the film structure is carried out by chemical crosslinking to prevent the resolubilization in water. Mastering this process is very appealing but needs to fully understand the interplay between phase separation, crosslinking and mass transfers as temperature is raised above the LCST. The membrane formation mechanisms has proven to be even more complex than for classical membranes since three phenomena take place concomitantly: phase separation, mass transfer due to evaporation and chemical crosslinking. Understanding and controlling the coupling between both phenomena is crucial for determining the best operating conditions leading to the target membrane morphology. In a previous paper dealing with the preparation of PVA/water membranes, our group exhibited that both the final temperature and the nature of the catalyzer strongly affect the final membrane morphology (either dense or porous). Indeed, the challenge was to ensure an efficient crosslinking after the membrane structure was fixed but before the composition path leaves the diphasic region and comes back to the monophasic region. A modeling approach could thus be very useful for better understanding the link between the mass transfers, the phase inversion and the chemical crosslinking reaction involved during the membrane formation.

During the last twenty years, several models have been developed to simulate the mass transfer phenomena in polymer systems, and hence to predict the composition path followed by the system during membrane formation. The simulation results have helped a better understanding of the final membrane morphology obtained in specific operating conditions. Anderson and Ulman published the first paper dealing with modeling approach for dry casting process ${ }^{17}$. The model has been improved year after year to take into account more precisely the boundary conditions ${ }^{18}$, then to consider the gas 
phase resistance to mass transfer and to introduce mutual diffusion coefficients rather than selfdiffusion ones ${ }^{19,20}$. Later, the coupling between mass and heat transfer has been integrated in the mode $^{22,23}$. Efforts have been also made about the diffusion formalism used in such models to predict more precisely the mass transfer rates during the phase separation ${ }^{24,25}$. Lee and coworkers integrated in their model a convective contribution to mass transfer due the density change in the solution ${ }^{26}$ and in specific cases, heat transfer within the solution was solved to obtain a non-uniform temperature along the membrane thickness ${ }^{22,27}$. Concerning VIPS process, recent models have been developed during the last decades, allowing to better understanding the relationship between the processing conditions and the final membrane morphology $28,29,30,31,32$.

Herein, we developed a numerical model based for mass transfers not only prior but also during phase inversion, in order to predict the composition path during LCST-TIPS process and to identify the best operating conditions for obtaining a porous membrane at moderate temperature. The numerical model takes into account both the solvent and catalyzer evaporation during the process and aims at simulating the composition path during the whole process, even after the phase separation started. In the first part of the paper, the system will be precisely defined and then the model will be described. In the second part, the model will be validated using experimental data, and in a third part the model will be used to identify the best operating conditions to form a porous structure.

\section{Material and methods}

\subsection{Materials}

A PVA with a degree of hydrolysis (DH) of $72 \%$ and a degree of polymerization (DP) of 672 was chosen for this study. PVA was supplied by Synthomer. Aqueous glutaraldehyde solution (25\%), hydrochloric acid (37\%) and sulfuric acid (95\%) were purchased from Sigma Aldrich and used as received. 


\subsection{Preparation of polymer solutions}

The aqueous solutions of PVA ( $10 \mathrm{wt} \%$ of polymer) were maintained at $80^{\circ} \mathrm{C}$ under stirring for $4 \mathrm{~h}$ to remove the crystalline structure of highly hydrolyzed $\mathrm{PVA}^{33}$, before they were cooled down under the LCST to dissolve the polymer. Prior to membrane preparation and characterization, all PVA solutions were kept for half a day at room temperature to remove air bubbles.

\subsection{Membranes preparation}

The whole membrane preparation procedure has been detailed in a previous paper ${ }^{16}$. PVA/GA solutions prepared at $10 \mathrm{wt} \%$ of PVA and $0.5 \mathrm{wt} \%$ of GA and using diluted hydrochloric or sulfuric acid were cast onto a glass plate with an automatic coater ( $\mathrm{K}$ coater Erichsen). The glass plate was rapidly put on a heating support at the desired temperature $\left(60,70\right.$ or $\left.80^{\circ} \mathrm{C}\right)$ in an elaborating chamber where the relative humidity was controlled (50\% $\mathrm{RH}$ in these experiments). The temperature ramp was fixed at $35^{\circ} \mathrm{C} / \mathrm{min}$.

\subsection{NMR measurements}

Pulsed field gradient NMR spectroscopy was used to measure self-diffusion of water in the polymer solution. By use of a gradient, molecules can be spatially labeled, i.e. marked on their position in the sample tube. If they move during the following diffusion time $(\Delta)$, their new position can be decoded by a second gradient. The measured signal is the integral over proton NMR peaks. The NMR signal intensity is attenuated depending of the diffusion time $(\Delta)$ and the gradient parameters $(g, \delta)$. This intensity change is described by:

$I=I_{0} \exp \left[-D \gamma^{2} g^{2} \delta^{2}(\Delta-\delta / 3)\right]$

2D-DOSY (Diffusion-Ordered Spectroscopy) NMR experiments were performed at different temperatures with a Bruker Dual z-gradient probe head capable of producing gradients in the $z$ direction with strength $55 \mathrm{G} \mathrm{cm}^{-1}$. The DOSY spectra were acquired with the dstebpgp3s pulse program 
(2D sequence for diffusion measurement), using double stimulated echo for convection compensation and LED, using bipolar gradient pulses for diffusion and using 3 spoil gradients ${ }^{34,35}$.

All spectra were recorded with 8 Ko time domain data points in the F2 Frequency axis and 16 experiments (F1). The gradient strength was logarithmically incremented in 64 steps from $2 \%$ up to $95 \%$ of the maximum gradient strength. All measurements were performed with a diffusion delay $\Delta$ of $50 \mathrm{~ms}$ in order to keep the relaxation contribution to the signal attenuation constant for all samples. The gradient pulse length $\delta$ was $2.2 \mathrm{~ms}$ in order to ensure full signal attenuation.

The diffusion dimension of the 2D DOSY spectra was processed by means of the Bruker Topspin software (version 2.1).

\subsection{Model description}

\subsubsection{Position of the problem}

The membrane formation mechanisms using the PVA/water system are quite different as those involved with classical polymer/solvent systems since the phase separation is induced by increasing the temperature above the Lower Critical Solution Temperature of the PVA/water system (LCST-TIPS process). As PVA is water soluble, a crosslinking step is necessary to prevent a solubilization in water during further use. A chemical crosslinking was performed here, using glutaraldehyde (GA) as crosslinker and chlorydric acid $(\mathrm{HCl})$ as catalyzer. It was demonstrated that the crosslinking reaction was rapid and occurred concomitantly with the phase inversion ${ }^{16}$. Since the phase separation process was conducted in open conditions (polymer solution exposed to air), mass transfers occurred during the process between the solution and the external environment, i.e. water and $\mathrm{HCl}$ evaporation. Consequently, three phenomena are coupled during membrane formation: (i) phase inversion, (ii) crosslinking, (iii) mass transfers from solution to air.

The model presented herein aims at better understanding the link between the process conditions and the final membrane morphology obtained by LCST-TIPS method, for the PVA/water system. In this respect, the mass transfers of both water and $\mathrm{HCL}$ evaporation will be described and modeled. 
After a preliminary discussion dealing with the modeling strategy, the geometry of the model will be presented and the thermodynamic laws used in the model will be described for both components; the mass transfer model will then be detailed: the continuity equation and the dimensionless analysis, the initial and boundary conditions, the diffusion formalism and finally the external mass transfer correlations.

\subsubsection{Modeling strategy}

In order to control the operating conditions, and hence the mass transfers between the casting solution and the external environment, the LCST-TIPS process was performed into a fabrication chamber were the relative humidity, the temperature ramp, the target temperature and the air flow was controlled.

Depending whether the system is in the homogeneous or diphasic region during the membrane preparation, different strategies were chosen: before phase separation, i.e. when the composition path was still in the monophasic region, mass transfer in the homogeneous polymer solution was considered, thus involving both Flory-Huggins theory for describing the thermodynamics of the polymer/solvent system, and a mutual diffusion formalism. Furthermore, when the composition path was in the diphasic region, Flory-Huggins theory was still used to determine the chemical potential of water and PVA. Assuming that the polymer concentration in the lean polymer phase was negligible, simple diffusion formalism for water and $\mathrm{HCl}$ in pseudo homogeneous solution was used in this phase. Besides, the small molecules were assumed not to diffuse in the rich polymer phase because of very high polymer concentration. Fig. 1 summarizes this modeling strategy, depending on the composition path in the phase diagram. In the monophasic region, classical diffusion equations dedicated to diffusion of small molecules in polymer solution were used; in diphasic region, we were only interested by the diffusion of small species in the lean phase mainly composed of water, assuming a good connectivity between the pores in formation. We assumed in this model that the impact of the chemical crosslinking on the diffusion rate of the small species was weak for two main reasons: first, 
the phase inversion was reached quite rapidly (less than $45 \mathrm{~s}$ ) and secondly, during this short period, we ca expect that the crosslinking was not sufficient to strongly reduce the diffusion ability of the small species. Once the phase inversion began (after the composition path crossed the cloud point curve) the diffusion occurred in the lean polymer phase, thus the crosslinking did not affect the diffusion rate.

The thin polymer solution ( $1 \mathrm{~mm}$ thick) was placed onto a heating plate, which was set at the targeted temperature $\left(60,70\right.$ or $\left.80^{\circ} \mathrm{C}\right)$. The calculation of the Biot number in those operating conditions, with free convection for air motion above the casting film, exhibited that the Biot number was much less than 0.01 . Flat temperature profiles were thus expected in the casting film and it was therefore not necessary to solve the heat transfer within the film. Nevertheless, a simulation of the temperature ramp was included in the model, from the ambient temperature $\left(20^{\circ} \mathrm{C}\right)$ to the final temperature. So, the impact of the temperature on the whole transfer parameters (thermodynamic parameters, diffusion and mass transfer coefficients...) were taken into account in the model. For instance, the diffusion coefficients of water and $\mathrm{HCl}$ were correlated to the film temperature at each time step.

\subsubsection{Geometry}

The geometry for mass transfer in this system corresponds to the experimental conditions for membrane formation (Fig. 2): the polymer solution was experimentally cast onto a glass plate $(1 \mathrm{~mm}$ height) and then placed onto a heating plate in the fabrication chamber where the relative humidity was controlled. One-directional diffusion along the vertical axis was assumed in the model. The gas phase next to the top side of the polymer solution was characterized by its temperature $T^{\infty}$ (gas temperature) and relative humidity $\mathrm{RH}$.

\subsubsection{Thermodynamics}

- Water

A thermodynamic model based on Flory Huggins theory was used to express the Gibbs free energy of mixing for the polymer/solvent system. Preliminary experiments were performed to verify that the additives (glutaraldehyde) did not affect the phase diagram of PVA/water system. Indeed, in a previous 
study, using a PerkinElmer - UV Lambda25 coupled with a Peltier temperature programmer, we demonstrated that the presence of GA in the polymer solution at such a low concentration ( $0.5 \mathrm{w} \%$ ) did not strongly affect the cloud point temperature (less than $2.8 \%)^{16}$. The Gibbs free-energy-of-mixing for PVA/water system can be expressed as:

$\frac{\Delta \mathrm{G}_{\mathrm{m}}}{\mathrm{RT}}=\mathrm{n}_{1} \ln \emptyset_{1}+\mathrm{n}_{2} \ln \emptyset_{2}+\chi \mathrm{n}_{1} \emptyset_{2}$

Where $\mathrm{n}_{i}$ and $\phi_{i}$ are the number of moles and volume fractions of component $\mathrm{i}, \mathrm{R}$ and $\mathrm{T}$ the universal constant and the temperature, respectively. $\chi$ is the solvent/polymer interaction parameter. Subscripts 1 and 2 refer to the solvent and the polymer, respectively.

The chemical potential of each component was calculated from the previous expression and is expressed as follows:

$\frac{\Delta \mu_{i}}{R T}=\frac{\partial}{\partial n_{i}}\left(\frac{\Delta \mathrm{G}_{\mathrm{m}}}{\mathrm{RT}}\right)_{n_{j}, j \neq i}$

For the solvent and the polymer, the expressions of the chemical potential are thus:

$\frac{\Delta \mu_{1}}{R T}=\ln \phi_{1}+\left(1-\frac{V_{1}}{V_{2}}\right) \emptyset_{2}+\chi \emptyset_{2}^{2}$

$\frac{\Delta \mu_{2}}{R T}=\ln \phi_{2}-\left(\frac{V_{2}}{V_{1}}-1\right) \phi_{1}+\chi \frac{V_{2}}{V_{1}} \phi_{1}^{2}$

$V_{1}$ and $V_{2}$ are the solvent and polymer molar volumes, respectively.

$-\mathrm{HCl}$

For modeling the mass transfer of $\mathrm{HCl}$, the thermodynamic model used in this study involves equilibrium data for water/HCl solutions at different temperatures, thus neglecting in a first approach the influence of the polymer on the equilibrium curve. Henry's law was therefore used in this model. 


\subsubsection{Determination of the interaction parameter between water and PVA}

The interaction parameter $\chi$ between PVA and water depends on the temperature and is classically expressed using the following equation:

$\chi=A+\frac{B}{T}$

$A$ and $B$ were determined using experimental data obtained at the thermodynamic equilibrium at different temperatures. In the system presented in this study, the phase separation is expected to occur once the temperature exceeds the LCST. At equilibrium, the chemical potential of each compound in the lean and rich phases is equal, expressed by:

$\left\{\frac{\Delta \mu_{i}}{R T}\right\}_{\text {lean }}=\left\{\frac{\Delta \mu_{i}}{R T}\right\}_{\text {rich }} i=1,2$

Replacing by the expression of the water chemical potential (Eq. 4) gives:

$\ln \left(\left\{\phi_{1}\right\}_{\text {lean }}\right)+\left(1-\frac{V_{1}}{V_{2}}\right)\left\{\phi_{2}\right\}_{\text {lean }}+\chi\left(\left\{\phi_{2}\right\}_{\text {lean }}\right)^{2}=\ln \left(\left\{\phi_{1}\right\}_{\text {rich }}\right)+\left(1-\frac{V_{1}}{V_{2}}\right)\left\{\phi_{2}\right\}_{\text {rich }}+\chi\left(\left\{\phi_{2}\right\}_{\text {rich }}\right)^{2}$

At a given temperature, the interaction parameter can therefore be deduced from Eq. 8:

$\chi=\frac{\ln \left(\frac{\left\{\phi_{1}\right\}_{\text {rich }}}{\left\{\phi_{1}\right\}_{\text {lean }}}\right)+\left(1-\frac{V_{1}}{V_{2}}\right)\left(\left\{\phi_{2}\right\}_{\text {rich }}-\left\{\phi_{2}\right\}_{\text {lean }}\right)}{\left(\left\{\phi_{2}\right\}_{\text {lean }}\right)^{2}-\left(\left\{\phi_{2}\right\}_{\text {rich }}\right)^{2}}$

For monodisperse polymer, the interaction parameter is easy to determine from the binodal curve (which is also the cloud point curve) because the composition of the lean and rich polymer phases can be directly deduced from the curve (Fig 3). However, for a polydisperse polymer, such as PVA, the cloud point curve does not represent the composition of both phases; in this case, different curves must be determined depending on initial polymer concentration (coexistence or binodal curves) (Fig 3). The phase diagram of the PVA/water system has been studied previously ${ }^{16}$, and the data of the phase composition depending of the initial polymer concentration were used in this study. Indeed, the interaction parameter was calculated using Eq. 9 for different initial polymer concentrations $\left(\phi_{2_{\text {init }}}\right)$ and different temperatures. An expression of the interaction parameter was obtained for each initial 
concentration, therefore different couples $A$ and $B$ were obtained and the final expression of the interaction parameter was thus given by:

$\chi=A\left(\phi_{2_{\text {init }}}\right)+\frac{B\left(\phi_{2_{\text {init }}}\right)}{T}$

With $V_{1} / V_{2}=1 / N$. Finally, using the data of the PVA phase diagram, the parameter $B$ was shown to weakly depend on the initial concentration, therefore the final expression of the interaction parameter was given by:

$\chi=\left[-0.013 \times \ln \left(\phi_{2_{\text {init }}}\right)+1.1563\right]-\frac{200.2}{T}$

Where $\phi_{2_{\text {init }}}$ is the initial volume fraction of PVA and T is the temperature.

\subsubsection{Mass transfer}

In this mass transfer model within the polymer matrix, several assumptions were made: (i) no transfer of polymer in the air, (ii) ideal gas behavior in the gas phase, (iii) gas-liquid equilibrium at the film/air interface, (iv) the excess of volume due to mixing was neglected. When the system is in the monophasic region, a diffusion formalism specific of diffusion in the polymer matrix was used. In the diphasic region, the diffusion coefficients were determined based on the assumptions of (i) pseudohomogeneous lean polymer phase and (ii) a good connectivity allowing diffusing up to the air/solution interface. Based on these assumptions, the mass transfer model equations for the solvent diffusion in the polymer solution were derived as follows:

$\frac{\partial \rho_{1}}{\partial t}-\frac{\partial}{\partial x}\left(-D \frac{\partial \rho_{1}}{\partial x}\right)=0$

Where $D$ is the mutual diffusion coefficient between the solvent and the polymer and $\rho_{\mathrm{i}}$ is the mass concentration of component $\mathrm{i}$, defined by:

$\rho_{i}=\frac{\phi_{i}}{\widehat{V}_{l}}$

$\widehat{V}_{i}$ is the partial specific volume of component $\mathrm{i}$. 
Due to solvent evaporation, the mass of the solution decreases during time, thus leading to a displacement of the upper boundary. A coordinate transform was therefore performed to fix the boundaries between 0 and 1 :

$X=\frac{x}{H(t)}$

Using this coordinate transform, Eq. 12 becomes:

$\frac{\partial \rho_{1}}{\partial t}-\frac{X}{H(t)} \frac{\partial H(t)}{\partial t} \frac{\partial \rho_{1}}{\partial X}-\frac{D}{H(t)^{2}}\left(-\frac{\partial \rho_{1}}{\partial \mathrm{X}}\right)=0$

\subsubsection{Initial and boundary conditions}

The initial conditions for this system are written as follows:

$\rho_{i}(0, X)=\rho_{i 0}, \quad i=1,2$

$H(0)=H_{0}$

At the substrate/solution interface, impermeable boundary conditions were considered:

$X=0,-\frac{\partial \rho_{i}}{\partial X}=0, \quad i=1,2$

At the air/solution interface, Neumann conditions were considered to take into account solvent evaporation:

$X=1,-\frac{D}{H(t)} \frac{\partial \rho_{1}}{\partial X}=J_{i g}=k_{1}\left(\rho_{1 g}^{i}\left(T^{i}\right)-\rho_{1 g}^{\infty}\left(T^{\infty}\right)\right)$

$\rho_{1 g}^{i}\left(T^{i}\right)$ is the water mass concentration in the gas phase at the air/solution interface (at the temperature of the solution $\mathrm{T}$ ) and $\rho_{1 g}^{\infty}\left(T^{\infty}\right)$ is the water mass concentration in gas phase at infinity (at temperature $\left.\mathrm{T}^{\infty}\right) \cdot k_{1}$ is the mass transfer coefficient for solvent transfer, which will be discussed later in the model description. 
The water concentration in gas phase bulk $\left(\rho_{1 g}^{\infty}\right)$ can be deduced from the relative humidity $(\mathrm{RH})$ in the bulk. The water concentration at the air/solution interface $\left(\rho_{1 g}^{\mathrm{i}}\right)$ depends on the water activity $a_{i}$

$\rho_{1 g}^{i}\left(T^{i}\right)=\frac{a_{1} P_{1}^{0}\left(T^{i}\right) M_{1}}{\mathrm{RT}}$

$\rho_{1 g}^{\infty}\left(T^{\infty}\right)=\frac{\mathrm{RH} P_{1}^{0}\left(T^{\infty}\right) M_{1}}{\mathrm{RT}}$

$P_{1}^{0}$ is the vapor pressure of component $\mathrm{i}$ and $\mathrm{M}_{1}$ is the molar mass of water. The activity is expressed from the chemical potential by:

$a_{i}=\exp \left[\frac{\Delta \mu_{i}}{R T}\right]$

The $\mathrm{HCl}$ concentration in the bulk gas phase is null; at the air/solution interface it is deduced from thermodynamic data ${ }^{36}$.

The position of the air/solution boundary can be determined by the following expression:

$\frac{d H(t)}{d t}=\sum_{i} \frac{J_{i g}}{\rho_{i}}$

where $\rho_{p}$ is the polymer solution density.

\subsubsection{Diffusion formalism}

In the monophasic region, i.e. before the composition path enters into the diphasic region $\left(T<T_{c}, T_{c}\right.$ the cloud point temperature) and after it leaves the diphasic region to go back to the monophasic region (at higher polymer concentration), the small molecules will diffuse in a concentrated polymeric matrix. In the last decades, several formalisms have been proposed to express the mutual diffusion coefficient involved in Eq. 12 and 15 as a function of the self-diffusion coefficients. Vrentas and Duda have proposed the first diffusion formalisms for binary solutions ${ }^{37,38}$, and the formalisms have been extended to ternary systems $\mathrm{s}^{21,39,40,41}$. For binary systems, Vrentas and Duda proposed an equation 
relating the mutual diffusion coefficient $(D)$ to the self-diffusion coefficient of water $\left(D_{1}\right)$ and to the thermodynamic properties of the polymer-solvent system ${ }^{42}$ :

$D=\frac{Q \emptyset_{2} D_{1}}{1-D_{1} / D_{1}^{*}}$

$Q=\rho_{1}\left(\partial \mu_{1} / \partial \rho_{1}\right)_{T, P} / R T$

$D_{1}^{*}=R T M_{1} / \rho_{1} \xi_{11} N_{A}^{2}$

In eq. $26, \mu_{1}$ and $\mathrm{M}_{1}$ are the chemical potential per mole and the molecular weight of the solvent, respectively. $R$ is the gas constant per mole, $\xi_{11}$ is a friction coefficient, $T$ is temperature, and $N_{A}$ is Avogadro's number. Nevertheless, the relationship between $D$ and $D_{1}$ was shown to be only valid for very low solvent concentrations (near $\mathrm{w}_{1}=0$ ); this is a strong limitation for our systems, whose polymer concentration are about 10/20 wt\%. Consequently, another model was used in this work, which extends the validity domain to a wider range of polymer concentration ${ }^{43}$. This model substitutes the denominator of Eq. 25 by the following expression:

$A+B \emptyset_{2}+C \emptyset_{2}^{2}+E \emptyset_{2}^{3}$

$\mathrm{A}, \mathrm{B}, \mathrm{C}$, and $\mathrm{E}$ are constants and they can be determined from restrictions on $D_{1} / D_{1}^{*}$ and on $D^{43}$. Finally the equation of the mutual diffusion coefficient related to the self-diffusion coefficient is given by:

$D=\frac{Q D_{1}}{\alpha \emptyset_{1}^{2}+\left(1-\emptyset_{1}\right)\left(1-2 \emptyset_{1}\right)}$

$\alpha=\frac{M_{1}}{M_{2}} \frac{\widehat{V}_{1}^{0}}{\widehat{V}_{20}}\left(\frac{D_{1}}{D_{2}}\right)_{\mathrm{w}_{1}=1}$

$\widehat{V}_{1}^{0}$ and $\widehat{V}_{20}$ are the specific volumes of the pure solvent and the partial specific volume of the polymer at $w_{1}=1$ (pure solvent), respectively. $D_{1}$ and $D_{2}$ are the self-diffusion coefficients of solvent and polymer at $\mathrm{w}_{1}=1$, respectively. Since the whole parameters were not available for PVA/water system, RMN data were used to determine the self-diffusion coefficient of water at different temperatures and 
different PVA volume fractions. $D_{2}\left(w_{1}=1\right)$ was estimated by well-known results for diffusional behavior in infinitely dilute polymer solutions ${ }^{44,45}$.

Using Flory-Huggins theory to describe the thermodynamics of the polymeric system, Eq. 25 can be expressed as:

$Q=\left(1-\emptyset_{1}\right)\left(1-2 \chi \emptyset_{1}\right)+\phi_{1} / y$

$y=M_{2} \widehat{V}_{20} / M_{1} \widehat{V}_{1}^{0}$

$\chi$ is the interaction parameter between polymer and solvent.

The values of the parameters used in the diffusion formalism are reported in Table 1 . The self-diffusion coefficient of pure solvent as a function of temperature was found in literature ${ }^{46}$.

\subsubsection{External mass transfer}

The external mass transfer coefficients were calculated by empirical correlations derived in free or forced convection. Free convection, which involves air motion that is induced by a density change in the vicinity of the air/solution interface, was chosen for these simulations since the experiments are commonly performed in such conditions.

The following correlation was used to express the mass transfer coefficient $k_{i}$ versus the Grashof number $G r^{23,47}$ :

$\frac{k_{i} L_{c} y_{a i r, l m}}{D_{i g}}=0,816\left(G r S c_{i}\right)^{0,2}$

The Grashof number $(G r)$ allows calculating free convection due to density difference caused by composition gradients and/or temperature gradients near the air/solution interface:

$G r=\frac{L_{c}^{3} g \beta(T) \rho_{\text {air }}^{2}(T)}{\mu_{\text {air }}^{2}(T)}\left|T^{i}-T^{\infty}\right|$

And the Schmidt number $\left(S c_{i}\right)$ is expressed as: 
$S c=\frac{v_{i}}{D_{i g}}$

$v_{\mathrm{i}}$ is the viscosity of the air at the interface, $T^{i}$ and $T^{\infty}$ are the temperatures at the interface and in the bulk, respectively. $D_{\text {ig }}$ is the diffusion coefficient of water or $\mathrm{HCl}$ in gas phase, $\mu_{\text {air }}$ and $\rho_{\text {air }}$ are the dynamic viscosity and the density of the air at the bulk temperature. $\mathrm{L}_{\mathrm{c}}$ is the characteristic length of the system (half the length of the casting solution in this case), $\beta$ is the dilatation coefficient of air, and $\mathrm{y}_{\mathrm{air}, \mathrm{lm}}$ is the mean log of molar fraction of air between the air and the interface.

The whole physicochemical properties used in the model were taken from handbook tables and the model takes into account the fact that the physico-chemical properties $\left(\mu_{\mathrm{air}}, \rho_{\mathrm{air}}, \beta\right)$ depend on the temperature.

The diffusion coefficients in gas phase were deduced form the following equation ${ }^{31}$ :

$$
\begin{aligned}
D_{i g} & =\frac{1,4310^{-7} T^{1,75}}{P M_{i, g}^{0,5}\left[\left(\sum V_{d}\right)_{i}^{1 / 3}+\left(\sum V_{d}\right)_{g}^{1 / 3}\right]^{2}} \\
\mathrm{M}_{\mathrm{i}, \mathrm{g}} & =\frac{2 M_{i} M_{g}}{M_{i}+M_{g}}
\end{aligned}
$$

\subsubsection{Numerical algorithm}

The system of partial differential equations that described the mass transfer phenomena were numerically solved in one-dimension (x-axis) using finite element software: COMSOL Multiphysics ${ }^{\circledR} 5.1$. The mesh was refined in the vicinity of the air/solution interface, i.e. in the region where the concentration gradients were expected to be the highest $(X=1)$. A variable time step was used in order to improve the numerical resolution. 


\section{Results and Discussion}

\subsection{Model validation}

\subsubsection{Characteristic time scales}

Before using the model to predict the composition path according to the operating conditions, it should be first validated using experimental data. Since it was quite impossible for this system to obtain local measurements during membrane formation, the model validation was performed using a specific experiment. Indeed, two characteristic time scales can be deduced by a visual observation: (i) the time at which the composition path enters the diphasic region because the phase separation induced a whiteness of the film, and later (ii) the time at which the system leaves the diphasic region if the crosslinking was not completed. Indeed, if the system leaves the diphasic region and go back to the monophasic region before the end of the crosslinking, the whiteness should disappear because of phase inversion reversibility. In this case, the residence time in the diphasic region can be experimentally deduced. If the crosslinking is efficient enough to fix the membrane morphology when the system is still in the diphasic region, the whiteness will be maintained even after the system crossed the cloud point curve to go back to the monophasic region.

For most of the experiments, the crosslinking was achieved when the composition path leaved the diphasic region, and hence the whiteness was observable until the end of the experiment. The SEM data obtained at various temperatures $\left(60^{\circ} \mathrm{C}, 70^{\circ} \mathrm{C}\right.$ and $\left.80^{\circ} \mathrm{C}\right)$ and for two different catalyzers $(\mathrm{HCl}$ and $\mathrm{H}_{2} \mathrm{SO}_{4}$ ) confirm this assertion (Fig. 4): $\mathrm{SEM}$ photographs reported in Fig. $4 \mathrm{~b}$ to $4 \mathrm{f}$ exhibit porous structures for these operating conditions.

However, the disappearing of the solution whiteness was observed for one specific operating condition tested, i.e. the experiments conducted at $60^{\circ} \mathrm{C}$ with a temperature ramp of $35^{\circ} \mathrm{C} / \mathrm{min}$, under $50 \% \mathrm{RH}$ and using $\mathrm{HCl}$ as the acidic catalyzer. Fig. 4a confirms this visual observation, since a dense membrane structure was observed for those specific experimental conditions. Moreover, the residence time in 
the diphasic region could be estimated (time between the appearance of the solution whiteness and its disappearance) in this particular case. In parallel, the model can predict the composition path in the same operating conditions (Fig. 5) and hence both experimental and numerical results were compared to validate the mass transfer model (Table 2). With regards to the time needed to cross the cloud point curve for the first time, i.e. the time necessary to enter in the diphasic region, the model was shown to be in good agreement with the experimental results ( $40 \mathrm{~s}$ for experiments and $46 \mathrm{~s}$ for simulation data). Visually, the disappearing of the whiteness was observed for the aforementioned operating conditions after about $580 \mathrm{~s}$. Concerning the numerical results, because of the solvent evaporation underlying the creation of concentration gradient, different time scales could be obtained depending on the height in the solution. As the composition paths are different at $\mathrm{X}=0$ (bottom) and $\mathrm{X}=1$ (air/solution interface), the residence times into the diphasic region are different too. Table 3 reports that at $X=0$, the numerical results predicts that the system reached the cloud point curve after $573 \mathrm{~s}$ but after only $421 \mathrm{~s}$ at $\mathrm{X}=1$. To compare to the experimental observations, the highest value should be kept since as long as a layer of the solution is in the diphasic region, the whiteness should be visible. Consequently, the model predicted that the residence time in the diphasic region is equal to $527 \mathrm{~s}$, in very good agreement with the experimental observations.

\subsubsection{Concentration profiles}

Fig. 5 exhibits that the composition paths are very different at the bottom and at the upper interface of the casting solution. This result arose from the creation of concentration gradients in the vicinity of the air/solution interface due to solvent evaporation. Indeed, the solvent evaporation led to an increase of the polymer concentration near the upper interface; since the diffusion within the solution is very slow (diffusion in homogeneous polymer solution), the diffusion rate of solvent from the bottom of the solution to the upper interface was not as rapid as its evaporation to the air. In this context, the composition path at the upper interface $(X=1)$ is deviated on the right side in Fig. 5 until the cloud point curve is reached at the bottom of the solution. Then, due to phase inversion, the diffusion of solvent was easier because water can diffuse easily within the lean polymer domains within the 
polymer matrix and the concentration gradients tend to decrease, thus deviating the composition path at $X=1$ on the left side before crossing the cloud point curve.

Fig 6. reports the simulated concentration profiles of polymer at increasing time scales (before and after the phase separation began), which allow illustrating this phenomenon: concentration gradients are formed in the vicinity of the upper interface before phase inversion (10 s, $20 \mathrm{~s}, 40 \mathrm{~s})$ and then once the phase inversion started, the concentration gradients were reduced because of faster diffusion of water toward the top of the casting polymer film (60 s, $100 \mathrm{~s}, 200 \mathrm{~s}, 300 \mathrm{~s})$. It should be noted that the concentration profiles formed in the homogeneous solution (prior phase inversion) are localized in a small region near the upper interface, thus validating the fact that the composition at the bottom of the cast solution was chosen for validating the model. Indeed, the nearly whole film was white and homogeneous.

Fig 7. represents the variation of the weight fractions of PVA at $X=0, X=1$ and the average weight fraction versus time. This figure confirms that before phase inversion the curves relative to $X=0$ and relative to the mean weight fraction are almost identical, which arises from the formation of strong concentration gradient localized in the vicinity of the upper interface. During this period, the polymer concentration at $\mathrm{X}=1$ is expected to rapidly increase because of solvent evaporation and slow diffusion within the polymer matrix $(0-46 \mathrm{~s})$. After phase separation and due to an increase of the diffusion coefficient, the solvent diffusion is easier in the polymer matrix (from the bottom to the upper surface) and therefore the PVA concentration is expected to increase in the whole casting solution (46-421 s). Once the composition path at the upper interface reaches the cloud point curve (around $420 \mathrm{~s}$ ), the solution is expected to change from diphasic to homogeneous due to phase inversion reversibility. So, the diffusion of solvent is reduced only locally first, but it is enough to create a barrier, and the PVA concentration is expected to strongly increase again because the solvent evaporation is now faster than its diffusion in the polymer solution. Since the cloud point curve is expected to be reached at different time scales depending on the depth in the casting solution, a front of phase separation fade- 
out will occur until $573 \mathrm{~s}$, time at which the whole solution is expected to be homogeneous because the cloud point curve is crossed in the whole solution (it corresponds to a polymer volume fraction of 0.175 in Fig. 5 and Table 2).

The reliability of the model developed in this work was thus demonstrated, allowing us to use it as a predictive tool for better understanding the relationship between the operating conditions and the membrane formation mechanisms.

\subsection{Influence of the final temperature on the composition path}

Our group previously demonstrated using an experimental approach that the final temperature could strongly affect the membrane morphology, the other parameters being identical ${ }^{16}$. Using $\mathrm{HCl}$ as the catalyzer, at $70^{\circ} \mathrm{C}$ and $80^{\circ} \mathrm{C}$, porous membranes were obtained whereas at $60^{\circ} \mathrm{C}$, a dense membrane was obtained, suggesting that the composition path went out of the diphasic region before the end of the crosslinking, i.e. before the membrane morphology was stabilized. A goal of this modeling approach was to explain these results using quantitative data on mass transfers occurring during the membrane preparation and the influence of external parameters on the final membrane morphology.

So, simulations were carried out for two other target temperatures: $70^{\circ} \mathrm{C}$ and $80^{\circ} \mathrm{C}$. For these simulations, in agreement with the experimental conditions of membrane formation, the initial solution thickness was not modified $(1 \mathrm{~mm})$ and the external parameters were kept constant (external temperature, relative humidity, air flow conditions). Fig. 8 represents the composition paths for final temperatures of $70^{\circ} \mathrm{C}$ and $80^{\circ} \mathrm{C}$ and the two positions in the system $(X=0$ and $X=1)$. Table 3 reports the characteristics time scales obtained from the simulation results. Fig. 8 demonstrates that the composition paths exhibit similar trends for the two different target temperatures. At the bottom of the system the composition path is exactly the same for both final temperatures since the composition did not change until the final temperature was reached (due to low diffusion, the effect of the evaporation at the upper boundary did not affect the bottom boundary yet). At the air/solution interface, the water evaporation affects the composition path and induces the formation of 
concentration gradients, as for a final temperature of $60^{\circ} \mathrm{C}$. The composition path at the upper interface is therefore deviated on the right side prior to phase inversion and once the cloud point curve is reached at the bottom $(X=0)$, the simulations exhibit that concentration gradients are expected to weaken, thus leading the composition path to enter in the diphasic region at $\mathrm{X}=1$.

Fig. 9 represents the PVA concentration profiles at increasing time scales for final temperatures of $70{ }^{\circ} \mathrm{C}$ and $80^{\circ} \mathrm{C}$ : before phase inversion (20 s and $45 \mathrm{~s}$ ) for both conditions and when the composition path was in the diphasic region for each point in the solution, i.e. at the upper interface and at the bottom ( $20 \mathrm{~s}$ to $350 \mathrm{~s}$ for $70^{\circ} \mathrm{C}$ and $20 \mathrm{~s}$ to $260 \mathrm{~s}$ for $80^{\circ} \mathrm{C}$ ). Those curves exhibit similar results as obtained at $60{ }^{\circ} \mathrm{C}$ with stronger concentration gradients near the upper interface at higher temperatures. The final time scales for plotting the profiles $\left(350 \mathrm{~s}\right.$ and $260 \mathrm{~s}$ at $70^{\circ} \mathrm{C}$ and $80^{\circ} \mathrm{C}$, respectively) correspond to the times just before the exit time from diphasic region. The profiles show that the higher the final temperature, the stronger the polymer concentration gradient, which is due to the fact that the evaporation rate increases with increasing temperature, as shown in Fig. 10. At $80^{\circ} \mathrm{C}$, the evaporation rate is two times higher than at $70^{\circ} \mathrm{C}$ and three times higher than at $60{ }^{\circ} \mathrm{C}$ at the plateau. The time to reach the plateau corresponds to the time needed to reach the target temperature, i.e. $68.6 \mathrm{~s}$ at $60^{\circ} \mathrm{C}, 85.7 \mathrm{~s}$ at $70{ }^{\circ} \mathrm{C}$ and $102.8 \mathrm{~s}$ at $80^{\circ} \mathrm{C}$. At the end of the plateau, the evaporation flux decreases once the composition path at the upper interface reaches the cloud point curve, because the upper part of the polymer solution will become homogeneous due to phase inversion reversibility, thus strongly reducing the diffusion coefficient of small molecules in the polymer matrix. Due to faster evaporation rate, this characteristic time scale is reached earlier at high temperature, i.e. $80^{\circ} \mathrm{C}$ in this case.

Finally, those curves demonstrate that the final temperature clearly affects the composition path and especially the residence time in the diphasic region. The model exhibited that a temperature increase of $10{ }^{\circ} \mathrm{C}$ induced a decrease of the residence time in the diphasic region by $45 \%$ between $60{ }^{\circ} \mathrm{C}$ and 
$70{ }^{\circ} \mathrm{C}$ and by approximately $33 \%$ between $70^{\circ} \mathrm{C}$ and $80^{\circ} \mathrm{C}$. This result confirmed that the evaporation rate, and hence the solvent loss rate, is not proportional to the target temperature.

\subsection{Influence of the catalyzer on the composition path and the membrane morphology}

In the same time, our group demonstrated in a previous paper that the final membrane morphology was directly linked to the choice of the catalyzer: using $\mathrm{H}_{2} \mathrm{SO}_{4}$, porous membranes were obtained whatever the final temperature $\left(60^{\circ} \mathrm{C}, 70^{\circ} \mathrm{C}, 80^{\circ} \mathrm{C}\right)$ whereas using $\mathrm{HCl}$, different morphologies were obtained at $60^{\circ} \mathrm{C}$ compared to $70^{\circ} \mathrm{C}$ and $80^{\circ} \mathrm{C}$ : at $70^{\circ} \mathrm{C}$ and $80^{\circ} \mathrm{C}$, a porous membrane was obtained as demonstrated by SEM observations, but at $60^{\circ} \mathrm{C}$ the final membrane morphology was dense. More precisely, a whiteness of the polymer solution was observed but after several minutes, the whiteness disappeared, suggesting the loss of porous structure, which was confirmed by SEM analysis. The following operating conditions were used for those experiments: initial temperature of $20^{\circ} \mathrm{C}$, temperature ramp of $35{ }^{\circ} \mathrm{C} / \mathrm{min}$, relative humidity of $50 \%$ and casting thickness of $1 \mathrm{~mm}$. Since porous membranes were obtained using $\mathrm{H}_{2} \mathrm{SO}_{4}$ as a catalyzer, the evaporation of $\mathrm{HCl}$ was suspected to be responsible of this loss of porous structure. Indeed, at $80^{\circ} \mathrm{C}$, the system was shown to stay a shorter time in the diphasic region than at $60^{\circ} \mathrm{C}$, but at the same time the crosslinking reaction is expected to be much faster, which could explain that the structure was stabilized faster.

On the contrary, at $60{ }^{\circ} \mathrm{C}$ and using $\mathrm{HCl}$, the crosslinking reaction was expected to be slower than at $80^{\circ} \mathrm{C}$, and probably too slow to fix the morphology before the system returns to the monophasic region. Fig. 11 presents the simulated loss of $\mathrm{HCl}$ during membrane formation due to its evaporation. These curves exhibit that the loss rate of $\mathrm{HCl}$ is rapid, since more than $20 \%$ of $\mathrm{HCl}$ is expected to evaporate after less than two minutes. The slope change observed during the first $50 \mathrm{~min}$ is due to fact that the composition path crosses the cloud point curve at this moment, thus inducing the phase inversion. In this case, the diffusion coefficients of small species (water and $\mathrm{HCl}$ ) in the lean polymer phase are much higher than in a homogeneous polymer solution (before phase separation). The characteristic time scales reported in Table 3 indicate that the system was expected to leave the 
diphasic region at $\mathrm{X}=0$ after $573 \mathrm{~s}$ at $60^{\circ} \mathrm{C}, 430 \mathrm{~s}$ at $70{ }^{\circ} \mathrm{C}$ and $309 \mathrm{~s}$ at $80^{\circ} \mathrm{C}$. At such time scales, the loss of $\mathrm{HCl}$ was about $88 \%$ for the three temperatures, thus confirming that its evaporation should have a strong effect on the crosslinking progress. These results allow a better understanding of the difficulty to maintain a porous structure during the membrane preparation when using $\mathrm{HCl}$ as catalyzer: at $60^{\circ} \mathrm{C}$, the crosslinking reaction is slower than at $70^{\circ} \mathrm{C}$ and $80^{\circ} \mathrm{C}$, implying a reduced crosslinking efficiency. At higher temperatures, the residence time in the diphasic region is smaller but the crosslinking reaction is expected to be faster, which could explain why the porous structure was preserved at $70^{\circ} \mathrm{C}$ and $80^{\circ} \mathrm{C}$ using $\mathrm{HCl}$ as the catalyzer.

Using $\mathrm{H}_{2} \mathrm{SO}_{4}$ as the catalyzer, the reduction of crosslinking efficiency was no more a problem since this catalyzer is not as volatile as $\mathrm{HCl}$. In this case, porous structures were obtained for all final temperatures tested (from $60^{\circ} \mathrm{C}$ to $80^{\circ} \mathrm{C}$ ).

\subsection{Influence of the solution thickness on the composition path}

Starting from an initial solution thickness of $1 \mathrm{~mm}$, the numerical results exhibited that concentration gradients could appear, especially in the vicinity of the air/solution interface because of solvent evaporation. By affecting the ratio surface/volume in the system, the initial solution thickness is also expected to have an influence of the mass transfers and hence on the global solvent loss.

With $\mathrm{H}_{\text {init }}=1 \mathrm{~mm}$, the simulation results showed that the system leaved the diphasic region after about $570 \mathrm{~s}$ and $310 \mathrm{~s}$ (at the bottom of the casting solution) for final temperatures of $60^{\circ} \mathrm{C}$ and $80^{\circ} \mathrm{C}$, respectively. At $80^{\circ} \mathrm{C}$, this time was sufficient to perform the crosslinking reaction as proved by the formation of a porous structure after complete membrane solidification. Decreasing the solution thickness would affect the composition path, the surface/volume ratio being all the higher since the thickness is low. Table 4 summarizes those results and exhibits that at the bottom of the solution the residence time in the diphasic region is expected to be reduced by $24 \%, 46 \%$ and $68 \%$ with initial thicknesses of $750 \mu \mathrm{m}, 500 \mu \mathrm{m}$ and $250 \mu \mathrm{m}$, respectively. With an initial thickness of $250 \mu \mathrm{m}$, the system stays about one minute and a half in the diphasic region (and even less at the air/solution 
interface), meaning that the time to perform an efficient crosslinking is strongly reduced. Besides, experimental results performed with thin solution $(250 \mu \mathrm{m})$ confirmed that it was not possible to obtain a porous structure even at high temperature $\left(80^{\circ} \mathrm{C}\right)$ and high temperature ramp $\left(35^{\circ} \mathrm{C} / \mathrm{min}\right)$ because of a too rapid evaporation rate

At the same time, reducing the solution thickness will reduce the concentration gradients along the vertical axis. Fig. 12 reports the PVA concentration gradients obtained by decreasing initial solution thicknesses (i) just before the composition path enters the diphasic region, i.e. $45 \mathrm{~s}$ in all cases (Fig. 12a) and (ii) just before the composition reaches the cloud point curve, i.e. before coming back to the monophasic region (Fig. 12b). Clearly, significant concentration gradients are created before the system enters the diphasic region since the mass transfer by diffusion into a polymeric solution is very slow. The higher the initial solution thickness, the higher the concentration gradient: for initial thicknesses of $1 \mathrm{~mm}, 750 \mu \mathrm{m}$ and $500 \mu \mathrm{m}$, the concentration gradients are located only near the air/solution interface, whereas at $250 \mu \mathrm{m}$ they are located on a depth of $40 \%$ of the whole thickness.

Later in the diphasic region, the concentration gradients are weaker since the system was separated in two phases, allowing faster diffusion of water in lean polymer phase. Nevertheless, concentration gradients were formed because of rapid evaporation, which were all the more marked since the initial thickness was high. For an initial thickness of $1 \mathrm{~mm}$, the numerical results exhibit that PVA concentration is $50 \%$ higher at the air/solution interface than at the solution/casting support interface. For an initial thickness of $250 \mu \mathrm{m}$, the difference between both locations is only close to $6 \%$, suggesting the formation of a more homogeneous final structure after membrane solidification.

\section{Conclusion}

Herein, a numerical model was developed, allowing a better understanding of the formation mechanisms of porous membranes from PVA/water system by LCST-TIPS process. The main objective was to explain to what extent the mass transfers involved during the membrane formation caused the 
disappearing of the porous structure observed in previous experiments conducted at $60^{\circ} \mathrm{C}$ and using $\mathrm{HCl}$ as the catalyzer. The numerical simulations presented in this paper demonstrated that the water evaporation and the catalyzer evaporation $(\mathrm{HCl})$ were responsible of this result, by diverting the composition path on the one hand and by reducing the crosslinking efficiency on the other hand. Indeed, the simulations exhibited that the residence time within the diphasic region was strongly linked to the final temperature targeted $\left(60,70\right.$ or $\left.80^{\circ} \mathrm{C}\right)$. The higher the final temperature, the lower the residence time, which decreased from $527 \mathrm{~s}\left(60^{\circ} \mathrm{C}\right)$ to $263 \mathrm{~s}\left(80^{\circ} \mathrm{C}\right)$ at the bottom of the solution and from $375 \mathrm{~s}\left(60^{\circ} \mathrm{C}\right)$ to $216 \mathrm{~s}\left(80^{\circ} \mathrm{C}\right)$ at the upper interface, where the solvent evaporation occurs. Furthermore, the simulations demonstrated that more than $80 \%$ of the initial amount of hydrochloride acid was expected to evaporate when the system went back to the monophasic region. Those two results provide a thorough understanding why dense membranes were obtained using $\mathrm{HCl}$ as the catalyzer when the final temperature was only of $60^{\circ} \mathrm{C}$. At higher temperatures, the chemical crosslinking was expected to be faster, thus leading to the formation of porous membranes. Additional simulations showed that the initial solution thickness could have a significant influence on the membrane formation dynamics. Reducing the initial solution thickness enhanced the surface area to volume ratio and consequently the impact of the mass transfers on the whole process.

As a consequence these simulations showed that using a volatile catalyzer as $\mathrm{HCl}$, the influence of the evaporation phenomena could dramatically limit the possibility to obtain a porous membrane. Moreover this works shows that for such complex formation mechanisms involving phase inversion, crosslinking and solvent (and potentially $\mathrm{HCl}$ ) evaporation, the operating conditions should be chosen carefully to ensure the formation of a porous structure that lead to stable porous membrane. This framework of simulation has then a predictive character which will be used to choose the appropriate operating conditions for preparing PVA membranes, to optimize the crosslinking reaction by maintaining the system enough time in the diphasic region while limiting the $\mathrm{HCl}$ evaporation. 


\section{Acknowledgment}

The authors would like to address acknowledgments to the French National Agency of Research (ANR) which supported this study through the project POMEWISO (ANR-10-CD2I-0012).

\section{Nomenclature}

\begin{tabular}{|c|c|}
\hline Subscripts & 1 (water), 2 (PVA) \\
\hline $\mathrm{DH}$ & PVA degree of hydrolysis \\
\hline DP & PVA degree of polymerization \\
\hline LCST & Lower Critical Solution Temperature \\
\hline TIPS & Temperature Induced Phase Separation \\
\hline GA & glutaraldehyde \\
\hline$\Delta \mathrm{G}_{\mathrm{m}}$ & Gibbs free-energy-of-mixing \\
\hline $\mathrm{n}_{i}$ & number of moles of component $i$ \\
\hline$\phi_{i}$ & volume fractions of component $i$ \\
\hline$w_{i}$ & mass fractions of component $i$ \\
\hline$\chi$ & PVA/water interaction parameter \\
\hline$\Delta \mu_{i}$ & chemical potential of component $\mathrm{i}$ \\
\hline$V_{\mathrm{i}}$ & molar volume of component i \\
\hline $\mathrm{T}$ & temperature \\
\hline $\mathrm{T}^{\infty}$ & femperature in gas phase (bulk) \\
\hline $\mathrm{T}^{\mathrm{i}}$ & temperature in gas phase (air/solution interface) \\
\hline
\end{tabular}




\begin{tabular}{|c|c|}
\hline$\rho_{\mathrm{i}}$ & mass concentration of component $\mathrm{i}$ in polymer solution \\
\hline$\rho_{1 g}^{\infty}$ & mass concentration of water in gas phase (bulk) \\
\hline$\rho_{1 g}^{\mathrm{i}}$ & mass concentration of water in gas phase (air/solution interface) \\
\hline$D$ & mutual diffusion coefficient in polymeric system \\
\hline$\widehat{V}_{l}$ & partial specific volume of component $i$ \\
\hline$x$ & spatial coordinate in vertical axis \\
\hline$X$ & spatial coordinate in vertical axis after coordinate transform \\
\hline$H$ & height of the casting solution \\
\hline$k_{1}$ & mass transfer coefficient of water \\
\hline$a_{i}$ & activity of component $\mathrm{i}$ in polymer solution \\
\hline$J_{i}^{g}$ & flux of component $i$ in gas phase \\
\hline$\rho_{i}$ & density of component $\mathrm{i}$ \\
\hline$\rho_{\text {air }}$ & density of air \\
\hline$D_{1}$ & solvent self-diffusion coefficient in polymer/solvent system \\
\hline$D_{2}$ & polymer self-diffusion coefficient in polymer/solvent system \\
\hline$\xi_{11}$ & friction coefficient \\
\hline$N_{A}$ & Avogadro number \\
\hline$M_{1}$ & Molar mass of solvent \\
\hline$\widehat{V}_{1}^{0}$ & specific volumes of the pure solvent \\
\hline$\widehat{V}_{20}$ & partial specific volume of the polymer at $w_{1}=1$ (pure solvent) \\
\hline$L_{c}$ & characteristic length of the system \\
\hline
\end{tabular}




\begin{tabular}{|l|l|}
\cline { 2 - 2 }$y_{\text {air }, l m}$ & $\begin{array}{l}\text { mean log of molar fraction of air between the air and the interface } \\
D_{i g}\end{array}$ \\
$\beta$ & Schmidt number in gas phase at the air/solution interface \\
& dilatation coefficient of air
\end{tabular}

\section{References}

1. Loeb S, Sourirajan S. Sea water demineralization by means of an osmotic membrane, Adv. Chem. Ser. 1962;38:117-132

2. Kesting RE. Synthetic Polymeric Membranes-A Structural Perspective, second ed., Wiley, New York, 1985

3. Mulder M. Basic Principles of Membrane Technology. Dordrecht:Kluwer Academic Publishers, 1997

4. Caneba GT, Soong DS. Polymer membrane formation through the thermal-inversion process. 1. Experimental study of membrane structure formation, Macromolecules 1985;18:2538-2545

5. Lloyd RD, Kinzer K, Tseng H. Microporous membrane formation via thermally induced phase separation. I. Solid-liquid phase separation, J Membr Sci. 1990;52:239-261

6. Lloyd RD, Kim S, Kinzer K. Microporous membrane formation via thermally-induced phase separation. II. Liquid-liquid phase separation, J Membr Sci. 1991;64:1-11

7. Shang M, Matsuyama H, Teramoto M, Lloyd DR, Kubota N. Preparation and membrane performance of poly(ethylene-co-vinyl alcohol) hollow fiber membrane via thermally induced phase separation. $J$ Membr Sci. 2000;179:91-100

8. Smolders CA, Reuvers AJ, Boom RM, Wienk IM. Microstructures in phase-inversion membranes. Part 1. Formation of macrovoids. J Membr Sci. 1992;73(2-3):259-275 
9. Stropnik Č, Germič L, Žerjal B. Morphology variety and formation mechanisms of polymeric membranes prepared by wet phase inversion. J of App Pol Sci. 1996;61(10):1821-1830

10. Kim YD, Kim JY, Lee HK, Kim SC. Formation of membranes by immersion precipitation. II Morphology formation. J of App Pol Sci. 1999;61:2124-2132

11. Matsuyama $H$, Teramoto $M$, Nakatani $R$, Maki T. Membrane formation via phase separation induced by penetration of nonsolvent from vapor phase. I. Phase diagram and mass transfer process. J App Pol Sci. 1999;74(1):159-170

12. Chae Park H, Po Kim Y, Yong Kim H, Soo Kang Y. Membrane formation by water vapor induced phase inversion. J Membr Sci. 1999;156(2):169-178

13. Caquineau H, Menut P, Deratani A, Dupuy C. Influence of the relative humidity on film formation by vapor induced phase separation. Pol Eng Sci. 2003;43:798-808

14. Menut P, Pochat-Bohatier C, Deratani A, Dupuy C, Guilbert S. Structure formation of poly (etherimide) films using non-solvent vapor induced phase separation: relationship between mass transfer and relative humidity. Desalination. 2002;145(1-3):11-16

15. Chinpa W, Bouyer D, Pochat-Bohatier C, Deratani A., Dupuy C. Effect of a drying pretreatment on morphology of porous poly(ether-imide) membrane prepared using vapor-induced phase separation. Drying Technology. 2006;24:1317-1326

16. M'barki O, Hanafia A, Bouyer D, Faur C, Sescousse R, Delabre U, Blot C, P. Guenoun P, Deratani A, Quemener D, Pochat-Bohatier C. Greener method to prepare porous polymer membranes by combining thermally induced phase separation and crosslinking of poly(vinyl alcohol) in water. $J$ Membr Sci. 2014;458:225-235

17. Anderson JE, Ulmann R. Mathematical analysis of factors influencing the skin thickness of asymmetric reverse osmosis membranes, J Appl Phys. 1973 ;44:4303-4311 
18. Castellari C, Ottani S. Preparation of reverse osmosis membranes. A numerical analysis of asymmetric membrane formation by solvent evaporation from cellulose acetate casting solutions, $J$ Membr Sci. 1981;9:29-41

19. Krantz WB, Ray RJ, Sani RL, Gleason KJ. Theoretical study of the transport processes occurring during the evaporation step in asymmetric membrane casting, J Membr Sci. 1986;29:11

20. Tsay CS, McHugh AJ. Mass transfer dynamics of the evaporation step in membrane formation by phase inversion, J Membr Sci. 1991;64:81-92

21. Alsoy S, Duda JL. Modeling of multicomponent drying polymer films. AIChE Journal. 1999;45(4):896905

22. Shojaie SS, Krantz WB, Greenberg AR. Development and validation of a model for the formation of evaporatively cast polymeric films, J. Mater. Process Manuf. Sci. 1992;1:181-194

23. Shojaie SS, Krantz WB, Greenberg AR. Dense polymer film and membrane formation via the drycast process part I. Model development. J Membr Sci. 1994;94(1):255-280

24. Altinkaya SA, Ozbas B. Modeling of asymmetric membrane formation by dry-casting method. J Membr Sci. 2004;230(1-2):71-89

25. Matsuyama H, Teramoto M, Uesaka T. Membrane formation and structure development by drycast process, J Membr Sci. 1997;135:271-288

26. Lee $H$, Chaudhuri SR, Krantz WB, Hwang ST. A model for evaporative casting of polymeric membranes incorporating convection due to density changes, J Membr Sci. 2006;284(1-2):161-172

27. Li D, Krantz WB, Greenberg AR, Sani RL. Membrane formation via thermally induced phase separation (TIPS): Model development and validation. J Membr Sci. 2006;279(1-2):50-60 
28. Matsuyama $H$, Teramoto $M$, Nakatani $R$, Maki T. Membrane formation via phase separation induced by penetration of nonsolvent from vapor phase. I. Phase diagram and mass transfer process. J App Pol Sci. 1999;74(1):159-170

29. Yip Y, McHugh AJ. Modeling and simulation of nonsolvent vapor-induced phase separation. J Membr Sci. 2006;271(1-2):163-176

30. Khare VP, Greenberg AR, Krantz WB. Vapor-induced phase separation--effect of the humid air exposure step on membrane morphology: Part I. Insights from mathematical modeling. J Membr Sci. $2005 ; 258(1-2): 140-156$

31. Bouyer D, Werapun W, Pochat-Bohatier C, Deratani A. Morphological properties of membranes fabricated by VIPS process using PEI/NMP/water system: SEM analysis and mass transfer modeling. J Membr Sci. 2010;349(1-2):97-112

32. Bouyer D, Pochat-Bohatier C. Validation of Mass-Transfer Model for VIPS Process using In-Situ Measurements Performed by Near-Infrared Spectroscopy. AIChE J. 2013;59(2):671-686

33. Briscoe B, Luckham P, Zhu S. The effects of hydrogen bonding upon the viscosity of aqueous poly(vinylalcohol) solutions. Polymer 2000;413:851-3860

34. Jerschow A., Müller N. 3D Diffusion-Ordered TOCSY for Slowly Diffusing Molecules. J. Magn. Reson. A $1996 ; 123: 222-225$

35. Jerschow A., Müller N. Suppression of convection artifacts in stimulated-echo diffusion experiments. Double-stimulated-echo experiments. J. Magn. Reson. A 1997; 125:372-375

36. Zhang Y, Zhou R. Vapor-Liquid Equilibria for Water + Hydrochloric Acid + Magnesium Chloride and Water + Hydrochloric Acid + Calcium Chloride Systems at Atmospheric Pressure. Chinese J. Chem. Eng., $2006 ; 14(2): 276-280$ 
37. Vrentas JS, Duda JL. Diffusion in polymer-solvent systems. I: Reexamination of the free-volume theory. J. Polym. Sci. Part B: Polym. Phys. 1977;15:403-416

38. Vrentas JS, Duda JL, Ling H-C. Self-diffusion in polymer-solvent-solvent systems. Journal of polymer science. Part A-2, Polymer physics. 1984;22(3):459-469

39. Yamamura M, TKajiwara T, Kage H. Multicomponent diffusion in phase-separation polymer blends with different frictional interactions: a mean-friction model. Chem. Eng. Sci. 2003;58:3891-3899

40. Zielinski JM, Hanley BF. Practical friction-based approach to modelling multicomponent diffusion. AIChE J. 1999;45:1-12

41. Price PE Jr, Romdhane IH. Multicomponent diffusion theory and its applications to polymer-solvent systems. AIChE J. 2003;49:309-322

42. Duda JL, Ni YC, Vrentas JS. An Equation Relating Self-Diffusion and Mutual Diffusion Coefficients in Polymer-Solvent SystemsMacromolecules. 1979;12(3):459-462

43. Vrentas JS, Vrentas CM. A new equation relating self-diffusion and mutual diffusion coefficients in polymer-solvent systems. Macromolecules. 1993;26:6129-6131

44. Yamakawa H. Modern Theory of polymer Solutions. NewYork:Harper and Row, Inc., 1971

45. Vrentas JS, Duda JL. Diffusion in infinitely dilute polystyrene solutions. J. Appl. Polym. Sci. $1976 ; 20: 1125-1131$

46. Tanaka K. Measurements of self-diffusion coefficients of water in pure water and in aqueous electrolyte solutions. J. Chem. Soc., Faraday Trans. 1975;71:1127-1131

47. Venault A, Bouyer D, Pochat C, Vachoud L and Faur C. Investigation of Chitosan Gelation Mechanisms by a Modeling Approach Coupled to Local Experimental Measurement. AIChE J. 2012; $7: 2226-2240$ 


\section{List of Tables}

1. Parameters used in the diffusion formalism

2. Model validation using experimental data $-\mathrm{T}_{\mathrm{i}}=20^{\circ} \mathrm{C}, \mathrm{T}_{\mathrm{f}}=60^{\circ} \mathrm{C}, \mathrm{RH}=50 \%$, Tramp $=35^{\circ} \mathrm{C} / \mathrm{min}$, Casting thickness $=1 \mathrm{~mm}$

3. Characteristic time scales for different target temperatures

4. Influence of the initial solution thickness on the time stayed in the diphasic region $-T_{i}=20^{\circ} \mathrm{C}$, $\mathrm{T}_{\mathrm{f}}=80^{\circ} \mathrm{C}, \mathrm{RH}=50 \%, \mathrm{Tramp}=35^{\circ} \mathrm{C} / \mathrm{min}$

\section{List of Figures}

1. Schematic of the modeling approach

2. Schematic of LCST-TIPS process

3. Phase diagram and coexistence curves pour PVA versus monodisperse polymer

4. SEM data for two catalyzers and three temperatures - $[\mathrm{PVA}]=10 \mathrm{wt} \%, \mathrm{~T}_{\text {ramp }}=35^{\circ} \mathrm{C} / \mathrm{min}$, $\mathrm{RH}=50 \%$, Casting thickness $=1 \mathrm{~mm}$

5. Composition path simulated by the model $-\mathrm{T}_{\mathrm{i}}=20^{\circ} \mathrm{C}, \mathrm{T}_{\mathrm{f}}=60^{\circ} \mathrm{C}, \mathrm{RH}=50 \%, \mathrm{~T}_{\mathrm{ramp}}=35^{\circ} \mathrm{C} / \mathrm{min}$, Casting thickness $=1 \mathrm{~mm}$

6. Concentration profiles simulated by the model $-T_{i}=20^{\circ} \mathrm{C}, T_{f}=60^{\circ} \mathrm{C}, \quad R H=50 \%$, $\mathrm{T}_{\text {ramp }}=35^{\circ} \mathrm{C} / \mathrm{min}$, Casting thickness $=1 \mathrm{~mm}$

7. Weight fraction of PVA versus time $-\mathrm{T}_{\mathrm{i}}=20^{\circ} \mathrm{C}, \mathrm{T}_{\mathrm{f}}=60^{\circ} \mathrm{C}, \mathrm{RH}=50 \%, \mathrm{~T}_{\text {ramp }}=35^{\circ} \mathrm{C} / \mathrm{min}$, Casting thickness $=1 \mathrm{~mm}$

8. Composition path simulated by the model $-\mathrm{T}_{\mathrm{i}}=20^{\circ} \mathrm{C}, \mathrm{T}_{\mathrm{f}}=70$ and $80^{\circ} \mathrm{C}, \mathrm{RH}=50 \%$, Tramp $=35^{\circ} \mathrm{C} / \mathrm{min}$, Casting thickness $=1 \mathrm{~mm}$

9. Simulated PVA concentration profiles prior to phase inversion (20 s, $45 \mathrm{~s})$ and when the composition path is in the diphasic region (60 to final time step just before leaving the diphasic region) $-\mathrm{T}_{\mathrm{i}}=20^{\circ} \mathrm{C}, \mathrm{T}_{\mathrm{f}}=70^{\circ} \mathrm{C}$ and $80^{\circ} \mathrm{C}, \mathrm{RH}=50 \%, \mathrm{~T}_{\text {ramp }}=35^{\circ} \mathrm{C} / \mathrm{min}$, casting thickness $=1 \mathrm{~mm}$ 
10. Water evaporation flux $-\mathrm{T}_{\mathrm{i}}=20^{\circ} \mathrm{C}, \mathrm{T}_{\mathrm{f}}=60^{\circ} \mathrm{C}, 70^{\circ} \mathrm{C}$ and $80{ }^{\circ} \mathrm{C}, \mathrm{RH}=50 \%, \mathrm{~T}_{\text {ramp }}=35^{\circ} \mathrm{C} / \mathrm{min}$, casting thickness $=1 \mathrm{~mm}$

11. Loss of $\mathrm{HCl}$ during membrane formation - ratio between $\mathrm{HCl}$ mass at time $\mathrm{t}$ to initial $\mathrm{HCl}$ mass - $\mathrm{T}_{\mathrm{i}}=20^{\circ} \mathrm{C}, \mathrm{T}_{\mathrm{f}}=60^{\circ} \mathrm{C}, 70^{\circ} \mathrm{C}$ and $80^{\circ} \mathrm{C}, \mathrm{RH}=50 \%, \mathrm{~T}_{\text {ramp }}=35^{\circ} \mathrm{C} / \mathrm{min}$, casting thickness $=1 \mathrm{~mm}$

12. PVA concentration profiles for increasing initial solution thickness; (a) just before the composition path enters the diphasic region; (b) just before the composition path leaves the diphasic region $-\mathrm{T}_{\mathrm{i}}=25^{\circ} \mathrm{C}, \mathrm{T}_{\mathrm{f}}=80^{\circ} \mathrm{C}, \mathrm{RH}=50$, Temperature ramp $=35^{\circ} \mathrm{C} / \mathrm{min}$ 


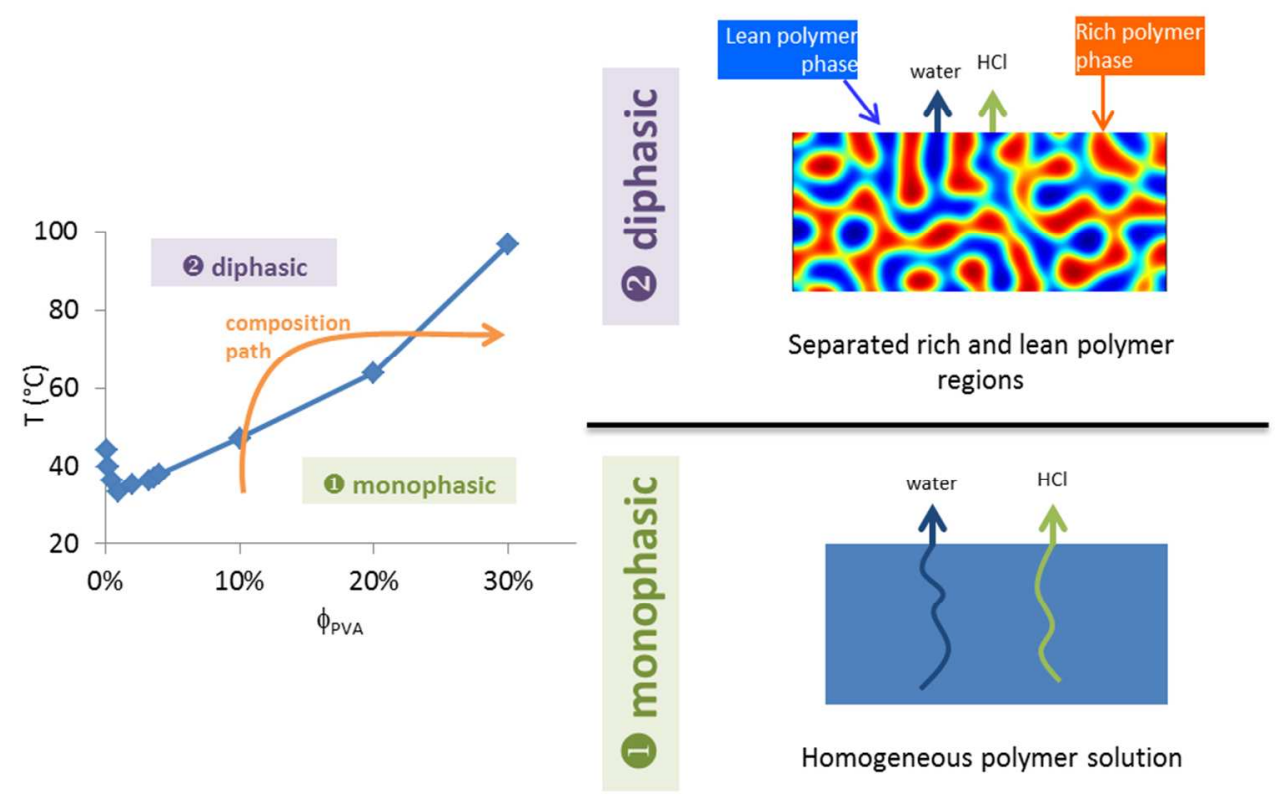

Schematic of the modeling approach

Fig. 1

$172 \times 113 \mathrm{~mm}(150 \times 150 \mathrm{DPI})$ 


\section{Gas phase: $\mathrm{RH}, \mathrm{T}^{\infty}$}

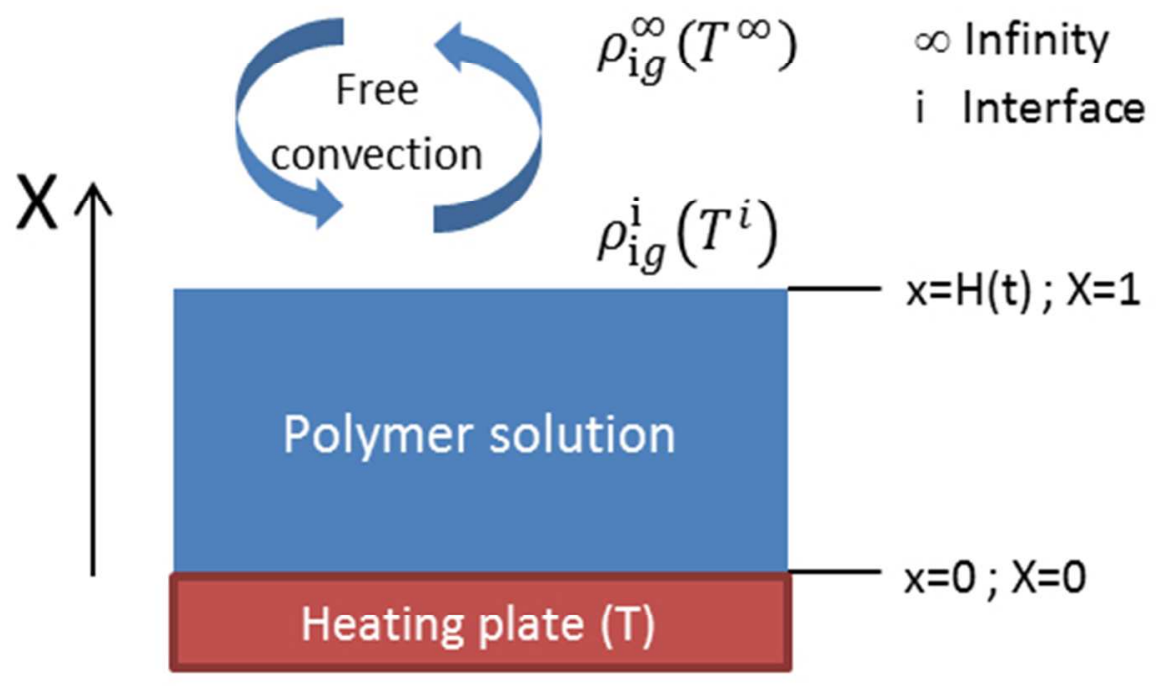

Schematic of LCST-TIPS process

Fig. 2

$95 \times 70 \mathrm{~mm}(150 \times 150 \mathrm{DPI})$ 


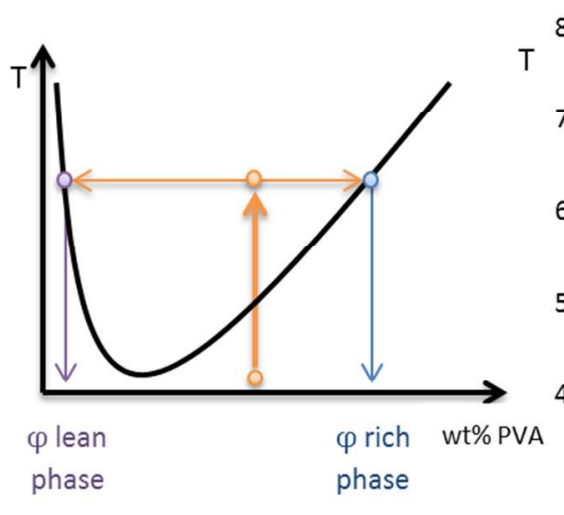

Monodisperse polymer

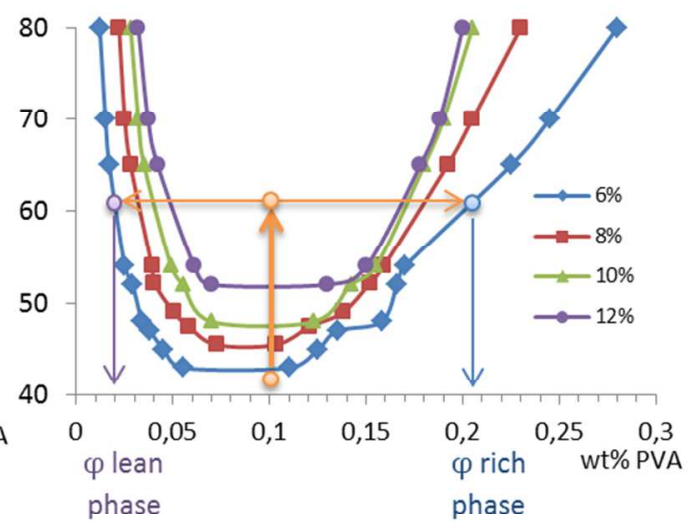

Polydisperse polymer (PVA)

Phase diagram and coexistence curves pour PVA versus monodisperse polymer Fig. 3 $163 \times 83 \mathrm{~mm}(150 \times 150 \mathrm{DPI})$ 


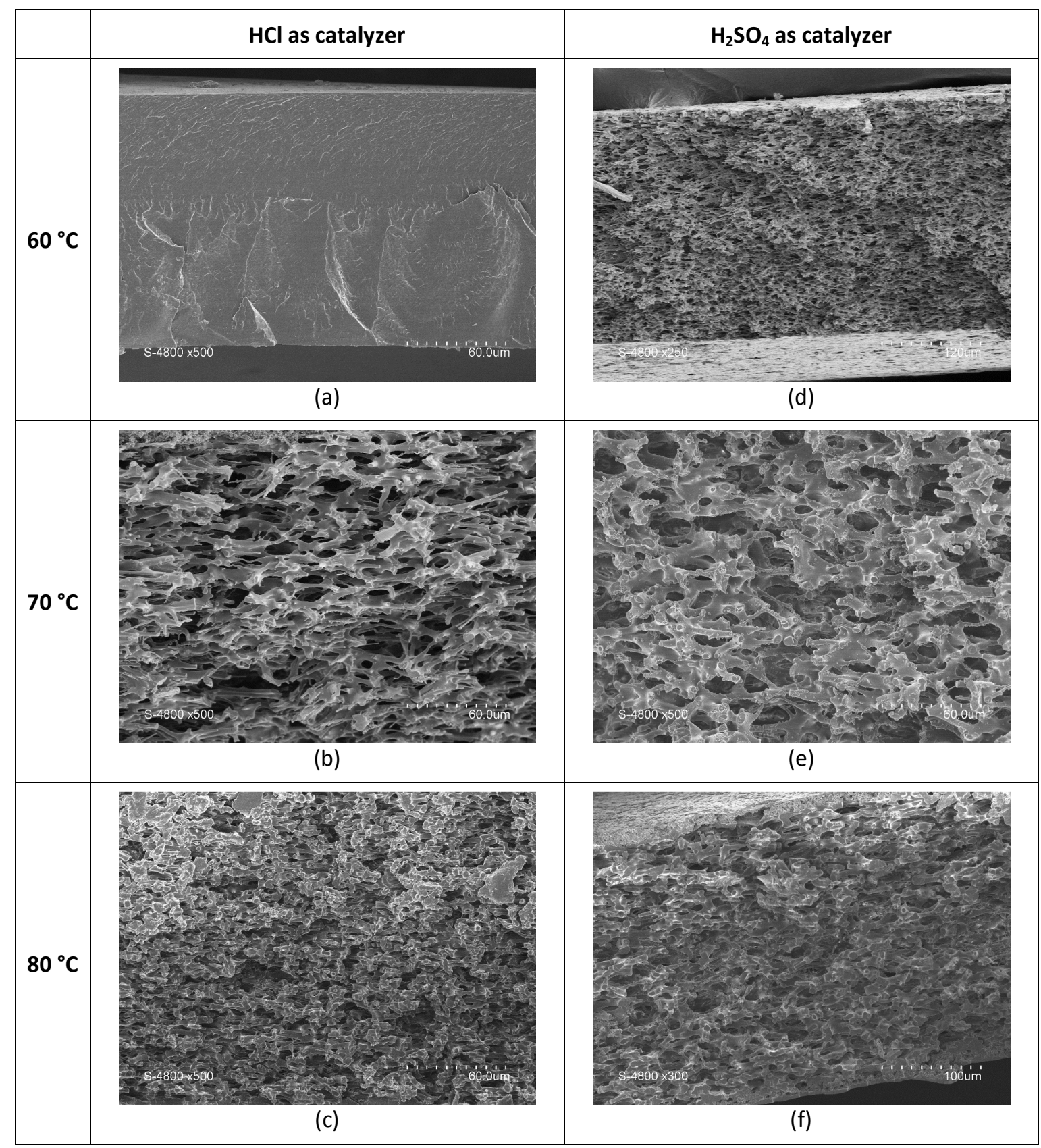




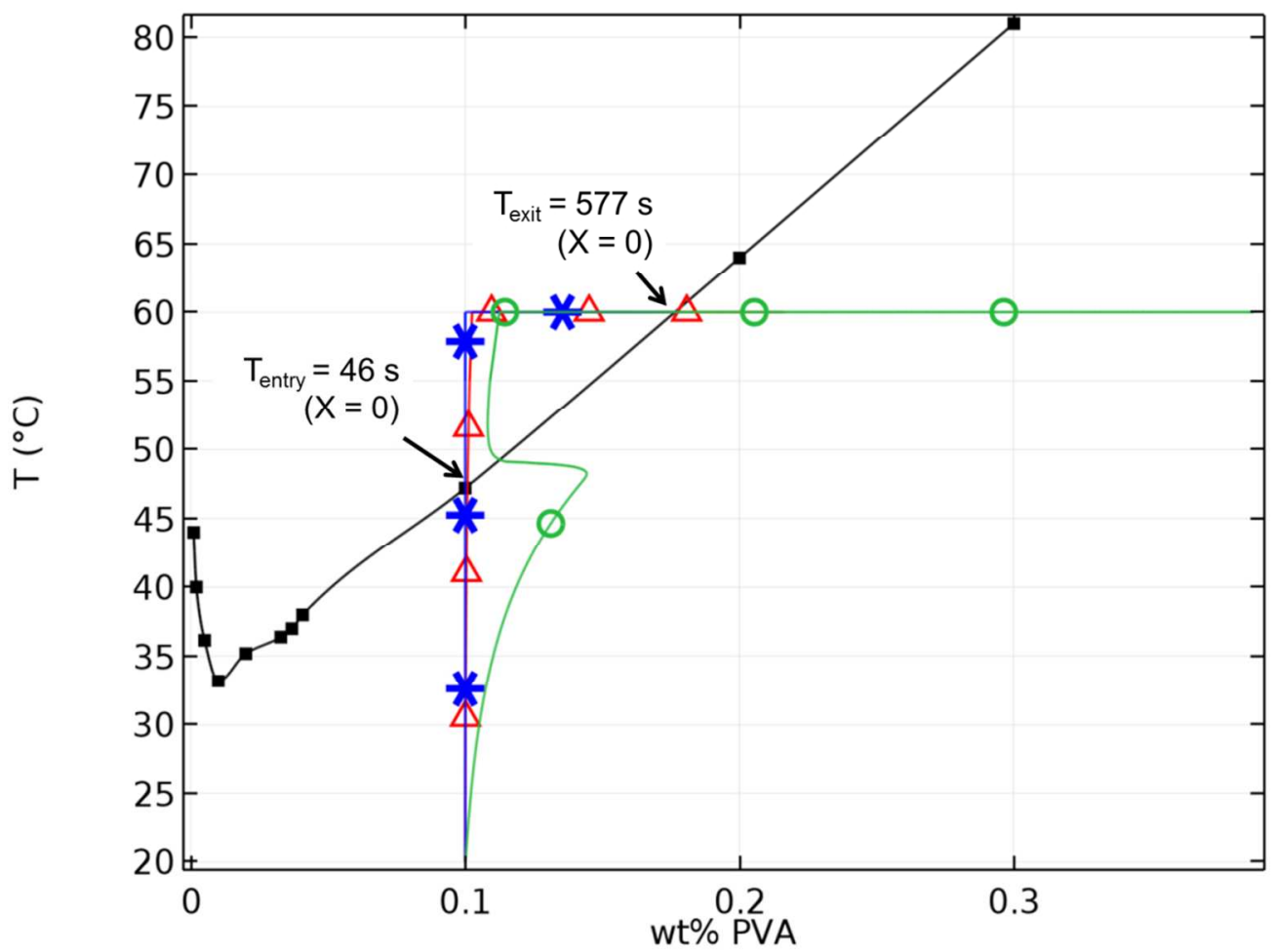

Composition path simulated by the model $-\mathrm{Ti}=20^{\circ} \mathrm{C}, \mathrm{Tf}=60^{\circ} \mathrm{C}, \mathrm{RH}=50 \%$, Tramp $=35^{\circ} \mathrm{C} / \mathrm{min}$, Casting thickness $=1 \mathrm{~mm}$

Fig. 5

$160 \times 120 \mathrm{~mm}(220 \times 220 \mathrm{DPI})$ 


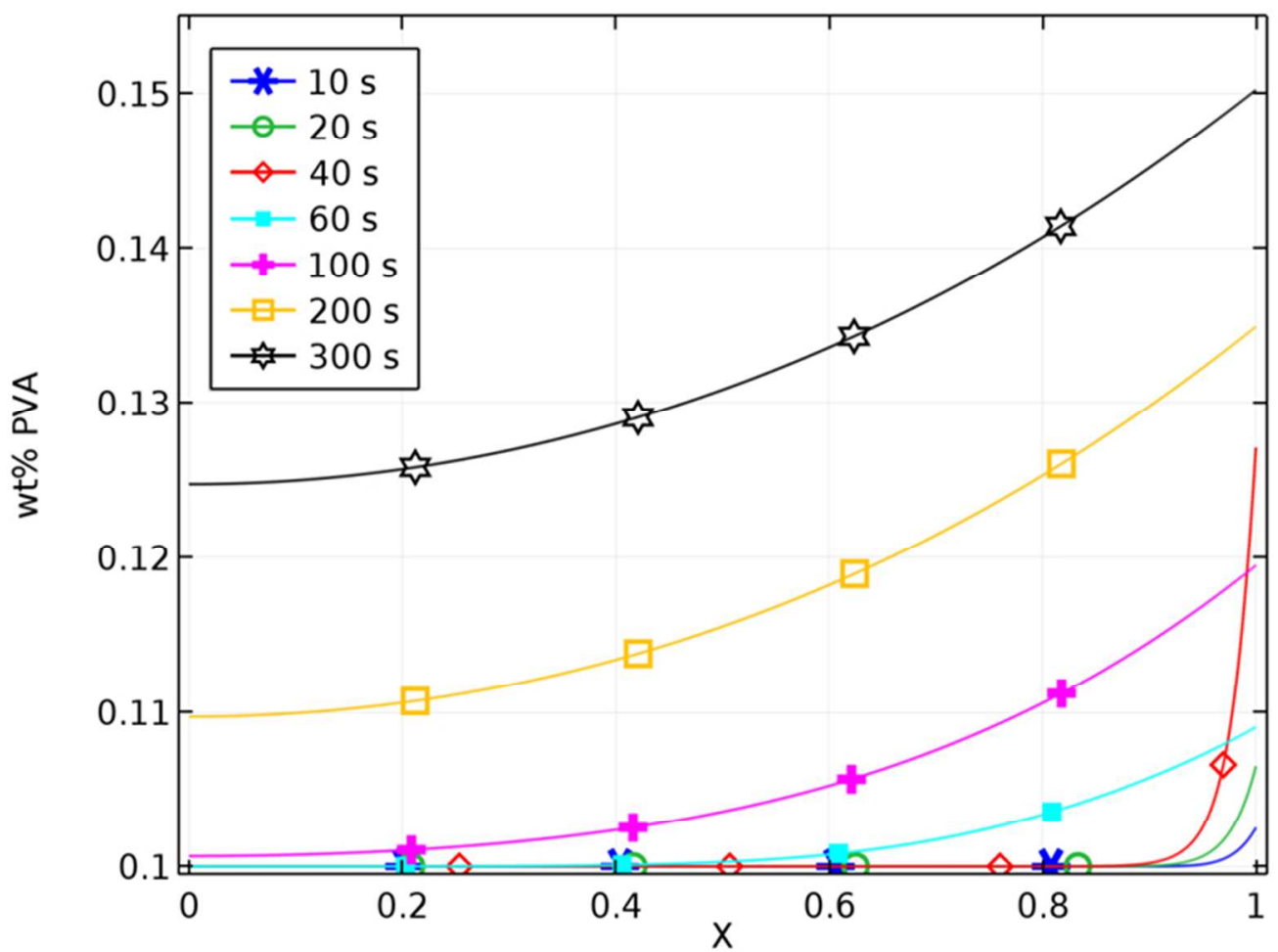

Concentration profiles simulated by the model $-\mathrm{Ti}=20^{\circ} \mathrm{C}, \mathrm{Tf}=60^{\circ} \mathrm{C}, \mathrm{RH}=50 \%$, Tramp $=35^{\circ} \mathrm{C} / \mathrm{min}$, Casting thickness $=1 \mathrm{~mm}$

Fig. 6

$135 \times 101 \mathrm{~mm}(150 \times 150 \mathrm{DPI})$ 


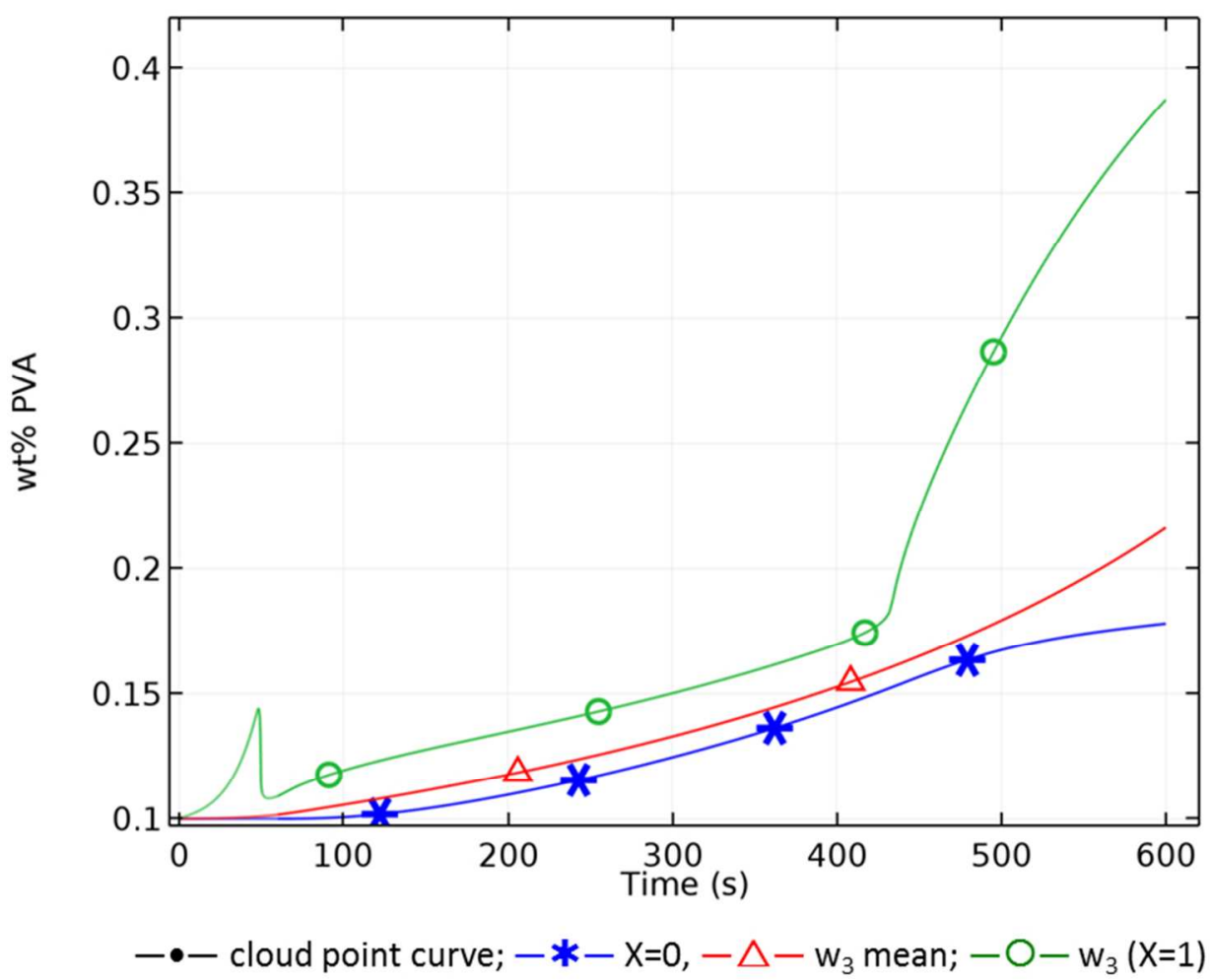

Weight fraction of PVA versus time $-\mathrm{Ti}=20^{\circ} \mathrm{C}, \mathrm{Tf}=60^{\circ} \mathrm{C}, \mathrm{RH}=50 \%$, Tramp $=35^{\circ} \mathrm{C} / \mathrm{min}$, Casting thickness $=1 \mathrm{~mm}$

Fig. 7

$143 \times 119 \mathrm{~mm}(150 \times 150 \mathrm{DPI})$ 


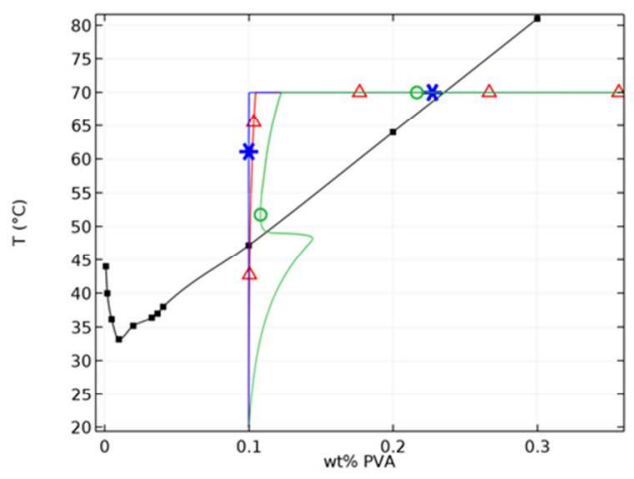

(a) $T_{f}=70^{\circ} \mathrm{C}$

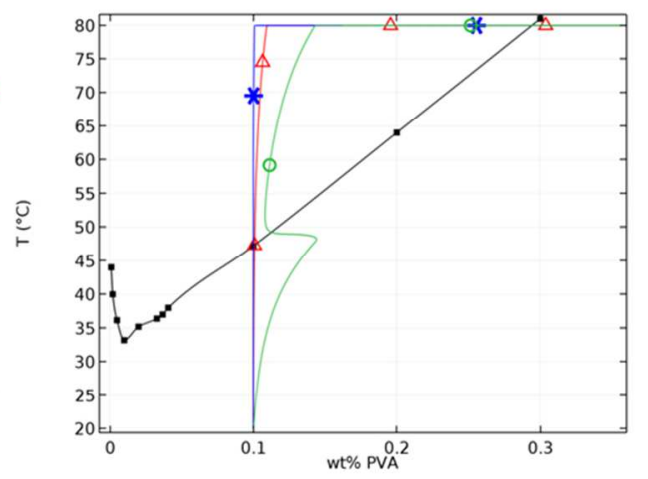

(b) $T_{f}=80^{\circ} \mathrm{C}$

$-\bullet$ cloud point curve; $-*-X=0,-\triangle-\mathrm{w}_{3}$ mean; $-\mathrm{O}-\mathrm{w}_{3}(\mathrm{X}=1)$

Composition path simulated by the model $-\mathrm{Ti}=20^{\circ} \mathrm{C}, \mathrm{Tf}=70$ and $80^{\circ} \mathrm{C}, \mathrm{RH}=50 \%$, Tramp $=35^{\circ} \mathrm{C} / \mathrm{min}$, Casting thickness $=1 \mathrm{~mm}$

Fig. 8

$167 \times 88 \mathrm{~mm}(150 \times 150 \mathrm{DPI})$ 


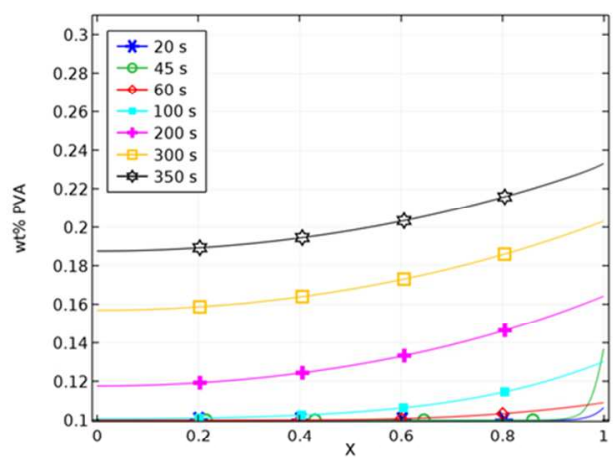

(a) $T_{f}=70^{\circ} \mathrm{C}$

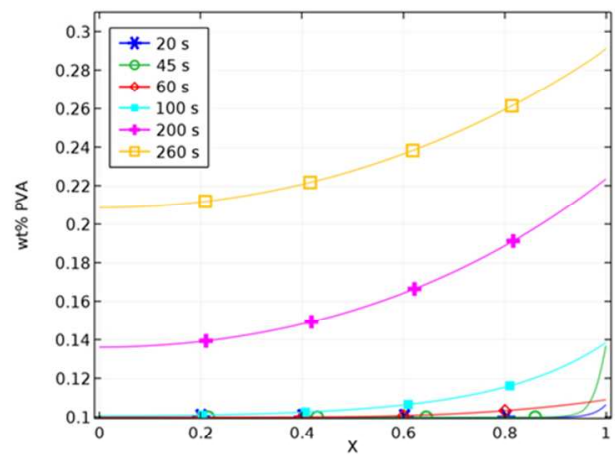

(b) $T_{f}=80^{\circ} \mathrm{C}$

Simulated PVA concentration profiles prior to phase inversion ( $20 \mathrm{~s}, 45 \mathrm{~s}$ ) and when the composition path is in the diphasic region ( 60 to final time step just before leaving the diphasic region) $-\mathrm{Ti}=20^{\circ} \mathrm{C}, \mathrm{Tf}=70^{\circ} \mathrm{C}$ and $80^{\circ} \mathrm{C}, \mathrm{RH}=50 \%$, Tramp $=35^{\circ} \mathrm{C} / \mathrm{min}$, casting thickness $=1 \mathrm{~mm}$

Fig. 9

$172 \times 76 \mathrm{~mm}(150 \times 150 \mathrm{DPI})$ 


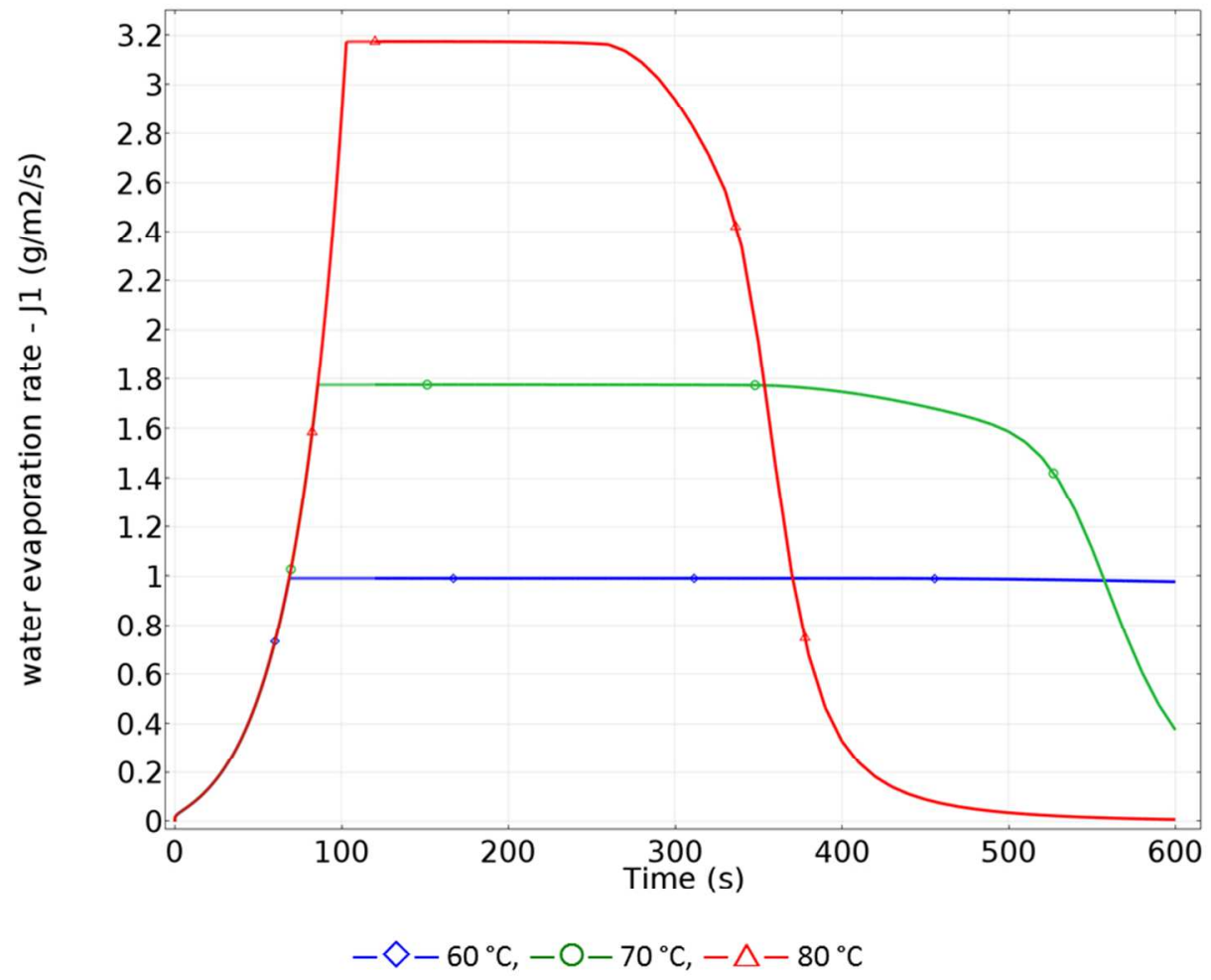

Water evaporation flux $-\mathrm{Ti}=20^{\circ} \mathrm{C}, \mathrm{Tf}=60^{\circ} \mathrm{C}, 70^{\circ} \mathrm{C}$ and $80^{\circ} \mathrm{C}, \mathrm{RH}=50 \%$, Tramp $=35^{\circ} \mathrm{C} / \mathrm{min}$, casting thickness $=1 \mathrm{~mm}$

Fig. 10

$174 \times 140 \mathrm{~mm}(150 \times 150 \mathrm{DPI})$ 


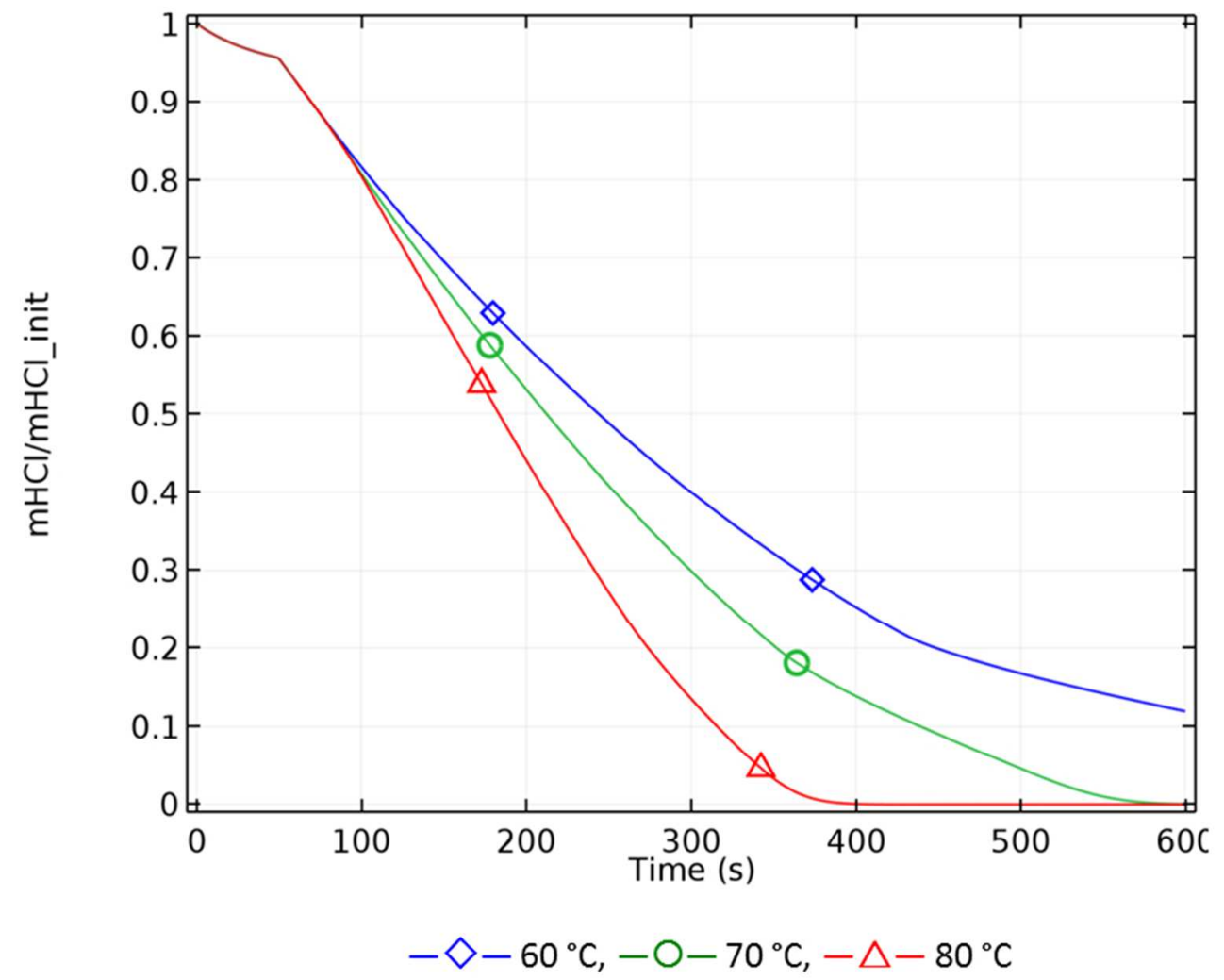

Loss of $\mathrm{HCl}$ during membrane formation - ratio between $\mathrm{HCl}$ mass at time $\mathrm{t}$ to initial $\mathrm{HCl}$ mass $-\mathrm{Ti}=20^{\circ} \mathrm{C}$, $\mathrm{Tf}=60^{\circ} \mathrm{C}, 70^{\circ} \mathrm{C}$ and $80^{\circ} \mathrm{C}, \mathrm{RH}=50 \%$, Tramp $=35^{\circ} \mathrm{C} / \mathrm{min}$, casting thickness $=1 \mathrm{~mm}$ Fig. 11 $139 \times 117 \mathrm{~mm}(150 \times 150 \mathrm{DPI})$ 


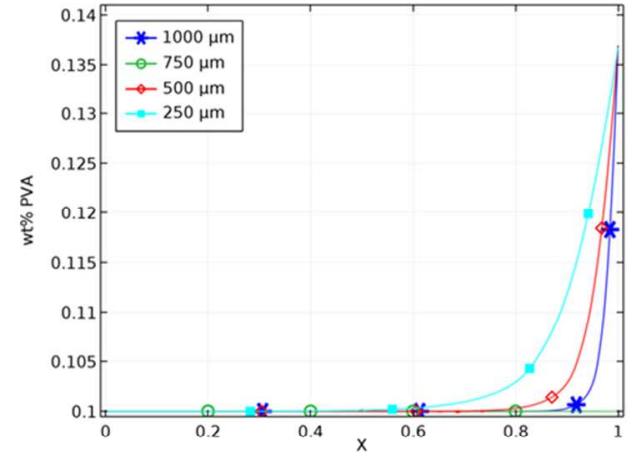

(a)

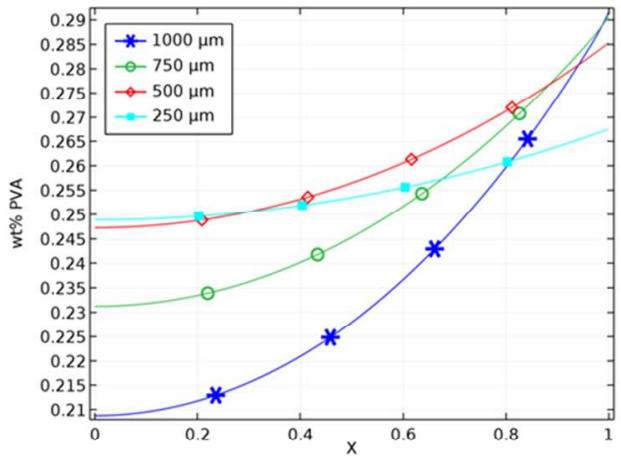

(b)

PVA concentration profiles for increasing initial solution thickness; (a) just before the composition path enters the diphasic region; (b) just before the composition path leaves the diphasic region $-\mathrm{Ti}=25^{\circ} \mathrm{C}, \mathrm{Tf}$ $=80^{\circ} \mathrm{C}, \mathrm{RH}=50$, Temperature ramp $=35^{\circ} \mathrm{C} / \mathrm{min}$

Fig. 12

$170 \times 73 \mathrm{~mm}(150 \times 150 \mathrm{DPI})$ 
Table 1. Parameters used in the diffusion formalism

\begin{tabular}{|c|l|}
\hline$\widehat{V}_{1}^{0}$ & $0.001 \mathrm{~m}^{3} \cdot \mathrm{kg}^{-1}$ \\
\hline$\widehat{V}_{20}$ & $7.5410^{-4} \mathrm{~m}^{3} \cdot \mathrm{kg}^{-1}$ \\
\hline$\left(D_{2}\right)_{\emptyset_{1}=1}$ & $710^{-11} \mathrm{~m}^{2} \cdot \mathrm{s}^{-1}$ \\
\hline $\mathrm{M}_{1}$ & $0.018 \mathrm{~kg} \cdot \mathrm{mol}^{-1}$ \\
\hline $\mathrm{M}_{2}$ & $80 \mathrm{~kg} \cdot \mathrm{mol}^{-1}$ \\
\hline
\end{tabular}


Table 2. Model validation using experimental data $-T_{i}=20^{\circ} \mathrm{C}, T_{f}=60^{\circ} \mathrm{C}, \quad R H=50 \%$, Tramp $=35^{\circ} \mathrm{C} / \mathrm{min}$, Casting thickness $=1 \mathrm{~mm}$

\begin{tabular}{|l|l|l|l|}
\hline & Experimental data & \multicolumn{2}{|l|}{ Simulation results } \\
\hline$t_{\text {entry }}$ & $40 \mathrm{~s}$ & $46 \mathrm{~s}$ & \multicolumn{2}{l|}{} \\
\hline$t_{\text {exit }}$ & $580 \mathrm{~s}$ & $\mathrm{x}=0$ & $573 \mathrm{~s}$ \\
$\mathrm{x}=1$ & $421 \mathrm{~s}$ \\
\hline$\Delta \mathrm{t}_{\text {diphasic }}$ & $540 \mathrm{~s}$ & $527 \mathrm{~s}$ & \\
\hline & & $x=0$ & $10.00 \%$ \\
$w_{3}$ at $t_{\text {entry }}$ & - & $x=1$ & $11.25 \%$ \\
\hline$w_{3}$ at $t_{\text {exit }}$ & - & $x=0$ & $17.65 \%$ \\
\hline
\end{tabular}


Table 3. Characteristic time scales for different target temperatures

\begin{tabular}{|l|l|c|c|c|}
\hline & & \multicolumn{3}{|c|}{ Simulation results } \\
\hline $\begin{array}{l}\text { Final temperate } \\
\text { targeted }\end{array}$ & & $60{ }^{\circ} \mathrm{C}$ & $70{ }^{\circ} \mathrm{C}$ & $80{ }^{\circ} \mathrm{C}$ \\
\hline $\mathrm{t}_{\text {entry }}$ & $\forall \mathbf{X}$ & $46 \mathrm{~s}$ & $46 \mathrm{~s}$ & $46 \mathrm{~s}$ \\
\hline $\mathrm{t}_{\text {exit }}$ & $\mathbf{X}=\mathbf{0}$ & $\mathbf{5 7 3 \mathrm { s }}$ & $\mathbf{4 3 0 \mathrm { s }}$ & $\mathbf{3 0 9} \mathrm{s}$ \\
\hline Residence time in \\
the diphasic region & $\mathrm{X}=\mathbf{X}$ & $421 \mathrm{~s}$ & $351 \mathrm{~s}$ & $262 \mathrm{~s}$ \\
\hline \multirow{2}{*}{$\mathrm{w}_{3}$ at $\mathrm{t}_{\text {entry }}$} & $\mathrm{X}=1$ & $\mathbf{5 2 7} \mathrm{s}$ & $\mathbf{3 8 4 \mathrm { s }}$ & $\mathbf{2 6 3 \mathrm { s }}$ \\
\hline \multirow{2}{*}{$\mathrm{w}_{3}$ at $\mathrm{t}_{\text {exit }}$} & $\mathrm{X}=0$ & $375 \mathrm{~s}$ & $305 \mathrm{~s}$ & $216 \mathrm{~s}$ \\
\hline
\end{tabular}


Table 4. Influence of the initial solution thickness on the time stayed in the diphasic region $\mathrm{T}_{\mathrm{i}}=20^{\circ} \mathrm{C}, \mathrm{T}_{\mathrm{f}}=80^{\circ} \mathrm{C}, \mathrm{RH}=50 \%, \mathrm{Tramp}=35^{\circ} \mathrm{C} / \mathrm{min}$

\begin{tabular}{|l|l|c|c|c|}
\hline \multicolumn{2}{|l|}{} & $\mathbf{7 5 0} \boldsymbol{\mu m}$ & $\mathbf{5 0 0} \boldsymbol{\mu m}$ & $\mathbf{2 5 0} \boldsymbol{\mu m}$ \\
\hline \multirow{2}{*}{$t_{\text {exit }}$} & $X=0$ & $247 \mathrm{~s}$ & $187 \mathrm{~s}$ & $130 \mathrm{~s}$ \\
\cline { 2 - 5 } & $X=1$ & $221 \mathrm{~s}$ & $176 \mathrm{~s}$ & $126 \mathrm{~s}$ \\
\hline \multirow{3}{*}{$\Delta t_{\text {diphasic }}$} & $X=0$ & $201 \mathrm{~s}$ & $141 \mathrm{~s}$ & $84 \mathrm{~s}$ \\
\cline { 2 - 5 } & $X=1$ & $175 \mathrm{~s}$ & $130 \mathrm{~s}$ & $80 \mathrm{~s}$ \\
\hline
\end{tabular}

